\title{
LOS GIMNASIOS DE BARCELONA DURANTE EL REINADO DE ISABEL II (1837-1868)
}

\author{
Gymnasiums in Barcelona during the Reign of \\ Isabella II of Spain (1837-1868)
}

\author{
Xavier Torrebadella Flix \\ xtorreba@gmail.com \\ Universidad Autónoma de Barcelona \\ Fecha de recepción: 15/03/2020 \\ Fecha de aceptación: 17/06/2020
}

\begin{abstract}
Resumen: Durante el período liberal español en la ciudad de Barcelona se manifestó la emergencia de una nueva culturalidad que nació de las eventualidades de una sociedad compleja y depositaria de signos históricos diferenciales. Esta culturalidad se manifestó en un crecimiento industrial, urbanístico y económico, pero también en las artes, las recreaciones y, además, en la ideológica y la política. En esta coyuntura y prestando atención a las transformaciones sociales, productivas y políticas europeas, en Barcelona se gestó el nacimiento de los primeros gimnasios higiénicos. La localización y el estudio de estos gimnasios es el objeto principal de este artículo, el cual ofrece un campo para poder interpretar mejor el nacimiento de las prácticas fisco-deportivas y sus relaciones sistémicas e ideológicas con otros acontecimientos históricos. La revisión de la prensa histórica depositada en la Biblioteca de Catalunya otorga la posibilidad de indagar en este análisis y coligar un discurso hermenéutico con el soporte de otros estudios de trasfondo y de contexto. Se concluye que la aparición de estos gimnasios no estuvo, en ningún caso, asociada a propósitos nacionalizadores y patrióticos, sino más bien al desarrollo urbano y moderno de un marco social privado y progresista.
\end{abstract}

Palabras clave: Barcelona; Período Liberal; gimnasios higiénicos; gimnástica; nacionalismo.

Abstract: During the Spanish liberal period in the city of Barcelona the emergency of a new style of culture which came as a result of a complex society with historical features that set it apart. This cultural style could be seen in industrial, urban and economic growth, but also in the arts, recreational activities and also in ideology and politics. Given these circumstances and with an eye on social change and advances in production, and European policies, in Barcelona the first hygienic gymnasiums began to appear. The localisation and study of these gymnasiums is the main objective of this paper, which provides a space to be able to better interpret the emergence of physical and sports practices and 
their systemic and ideological relationship with other historical events. A review of the historical press deposited in the Library of Catalonia offers the possibility of more in-depth analysis and links the hermeneutic discourse to the support of other background and contextual studies. It is therefore concluded that the appearance of these gymnasiums was never associated with nationalising and patriotic ends, but with the modern, urban development of a liberal and private social framework.

Keywords: Barcelona; Liberal Period; hygienic gymnasiums; gymnastics; nationalism.

SUMARIO: 1. Introducción. 2. Antes unas cuestiones político-sociales previas y de fondo. 3. Sobre el discurso medular de la gimnástica. 4. Sobre los primeros gimnasios de Barcelona. 5. Conclusiones. 6. Referencias.

\section{INTRODUCCIÓN}

Hacia mediados del siglo XIX se esparcen por Europa los discursos sobre el temor de la degeneración física y moral de la especie humana. Estos discursos responden a una construcción imaginaria que nace y se reproduce en la sociedad medio burguesa (Vigarello, 2005). En Francia, es Nicolas Dally (1795-1862) quien impele este discurso degeneracionista, el cual evoca a las creencias de las enfermedades hereditarias difundidas por el vicio y la miseria de las clases empobrecidas (Dally, 1848). Aprovechándose de los avances terapéuticos de la gimnástica médica, Dally contraponía los hábitos de una gimnástica racional, fuera de las manifestaciones acrobáticas predominantes, a las costumbres sociales viciadas y apoltronadas de la época. Este se posicionaba a favor de la gimnasia sueca de Per Henrik Ling (17761839), pero también del sistema de Hipólito Triat, con el que compartía la dirección de un majestuoso gimnasio en París (Andrieu, 1992; Prot, 2010; Torrebadella-Flix, 2020a).

España no quedó ajena a estos discursos y también se hablaba de «La regeneración física de la especie humana por medio de la gimnasia racional» (1848, p. 2). En estos momentos se iniciaba un proceso de continuas críticas dirigidas a la gimnástica basada en elementos de fuerza y de suspensión del cuerpo, y los médicos se galvanizanban de una configuración conceptual y técnica de la gimnástica apropiándose de una disciplina que comienzan a llamar racional o higiénica (Vicente-Pedraz y Brozas-Polo, 2017; Vicente-Pedraz y Torrebadella-Flix, 2019). Más tarde es Morel (1857) quien corona el discurso del regeneracionismo induciendo sus consecuencias y relaciones a nivel físico, intelectual y moral (Vigarello, 2005).

No obstante, en Francia la sociedad parisina ponía de moda las prácticas de sport, como así también lo hacía la vecina Inglaterra (Chapus, 1854). Y, por lo que respecta a España, en Barcelona este ambiente empezaba a visibilizarse en una reducida representación alrededor de los socios del Círculo Ecuestre, fundado en 1856; el Círculo de Ajedrez, en 1860; el Círculo Gimnástico Barcelonés, en 1860 o el Círculo de Cazadores, en 1861 (Torrebadella-Flix, Olivera-Betrán y M-Bou, 2015). 
Aparte, durante estos años viajan por España compañías gimnásticas, entre estas también de extranjeras, algunas de las cuales ocuparon espectáculos estables en ciudades como Madrid o Barcelona. Durante varias décadas, estos espectáculos de gimnástica funambulesca fueron muy populares y de aquí emergieron escuelas gimnásticas que, a la vez de perfeccionar el arte escénico, fueron convirtiéndose, paulatinamente, en los primeros gimnasios recreativos e higiénicos (Torrebadella, 2013a).

Barcelona fue un importante feudo de este tipo de compañías y, como trataremos, los primeros gimnasios asentados en la ciudad muestran la transición del ejercicio acrobático y recreativo al ejercicio gimnástico higiénico, médico y ortopédico. Solamente hace falta revisar la prensa de los años cuarenta del siglo XIX -Diario de Barcelona, El Constitucional, El Guardia Nacional, La Corona, El Imparcial, El Barcelonés...- para apreciar la significativa presencia y popularidad estos espectáculos.

Sobre esta coyuntura social se concentra la finalidad de este estudio, es decir, el divulgar conocimientos acerca de la aparición de los primeros gimnasios en Barcelona durante el llamado Período Liberal (1842-1868) con el objetivo de considerar las bases sociales y culturales que apuntalaron la aparición del movimiento gimnástico deportivo de finales del siglo XIX. Por otro lado, situamos la hermenéutica histórica en la configuración ideológica de la política liberal del momento y accedemos a relacionar el objeto de estudio con la construcción de los nacionalismos europeos.

Se coincide con Jaume Balmes (1810-1848), cuando sostenía que hasta entonces la historia siempre se había considerado desde las efemérides de una política de superficie, y poco se había tratado sobre los tantos acontecimientos recónditos en los que la naturaleza de las cosas reviste una suma importancia (Balmes, 1851). Sin embargo, en los momentos actuales, como apuntó Fontana (2015, p. 436), ciertamente hemos de convenir en que «la narración de la historia de España en estos años está hecha también, y, sobre todo, de silencios», que van más allá de los sucesos tradicionalmente aceptados. Por eso, como historiador comprometido, se lamentaba de no interrogar lo suficientemente a «los testigos pasivos de los acontecimientos", a los seres que sufren colectivamente las adversidades y que casi siempre son derrotados silenciosamente (Fontana, 2015, p. 436). De aquí brota este interés por atender también a estos elementos sumergidos que deberían contribuir a desvelar, en parte, los verdaderos enigmas de la historia.

En este estudio se ha utilizado una metodología histórica-hermenéutica elaborada a través de las fuentes primarias localizadas en el Arxiu de Revistes Catalanes Antigues (ARCA) -especialmente revisando el Diario de Barcelona- y en la Hemeroteca digital de la Biblioteca Nacional de España. Naturalmente, las informaciones obtenidas se han procesado en una trama argumental positivista y descriptiva que, con el apoyo original de los textos históricos y de una significativa bibliografía historicista, redimensiona el campo social del estudio. 


\section{ANTES UNAS CUESTIONES POLÍTICO-SOCIALES PREVIAS Y DE FONDO}

Con la muerte de Fernando VII, durante el Periodo Liberal se desató una permanente crisis de Estado con el desenlace de tres guerras civiles (octubre 1833-julio 1840 / 1846-1849/ 1872-1876). El reinado de Isabel II - «La frescachona» - (18331868), una marioneta en manos de generales militares y una sucesión de gobiernos dispares y corruptos, se enfrentó a una crisis permanente de Estado caracterizada por los numerosos levantamientos militares -golpes de Estado-. No obstante, durante este periodo se produjo una redefinición del ejército, que pasó a ejercer tres de las funciones que a partir de entonces fueron la substancia que legitimaba la existencia utilitaria del poder: la protección de la monarquía, la defensa de la unidad nacional y la protección la Constitución.

Las revoluciones obreras que afectaron principalmente a Cataluña, entre los años 1854 a 1856, marcados especialmente por el carácter de la primera huelga general en España, en 1854, fueron el detonante de una crisis económica y política, cuyo proceso revolucionario (1866-1868) provocó, en 1868 -La Gloriosa-, la expatriación de Isabel II y, posteriormente, la constitución de la Primera República -febrero 1873-diciembre 1874-. En estos años, la política exterior se caracteriza por los conflictos internacionales -guerra en Marruecos (1859-1860), y otros ruinosos escenarios bélicos en la Conchinchina (1858-1862), en México (1861-1862), en el Pacífico (1865-1866) y la primera guerra de liberación nacional de Cuba (1868-1878)...- aparte de las importantes pérdidas económicas y de las miles de bajas humanas, se fraguó en una represión interna que provocó una irreparable animadversión del pueblo a lo militar. Lo peor para la Monarquía fue la aureola republicana que subyacía en las populares revueltas urbanas. Sobre esta situación, la conciencia en determinadas capas de las clases subalternas puso en marcha una mayor autonomía y el despertar de una cultura propia, que cristalizó en un significativo proceso asociacionista (casinos, círculos, ateneos...). Así, la cultura popular se manifestaba en círculos teatros, agrupaciones de corales y musicales, asociaciones de baile, círculos recreativos, literarios, científicos y artísticos, sociedades filantrópicas y de beneficencia y, también, en sociedades gimnásticodeportivas [Figura 1]. 


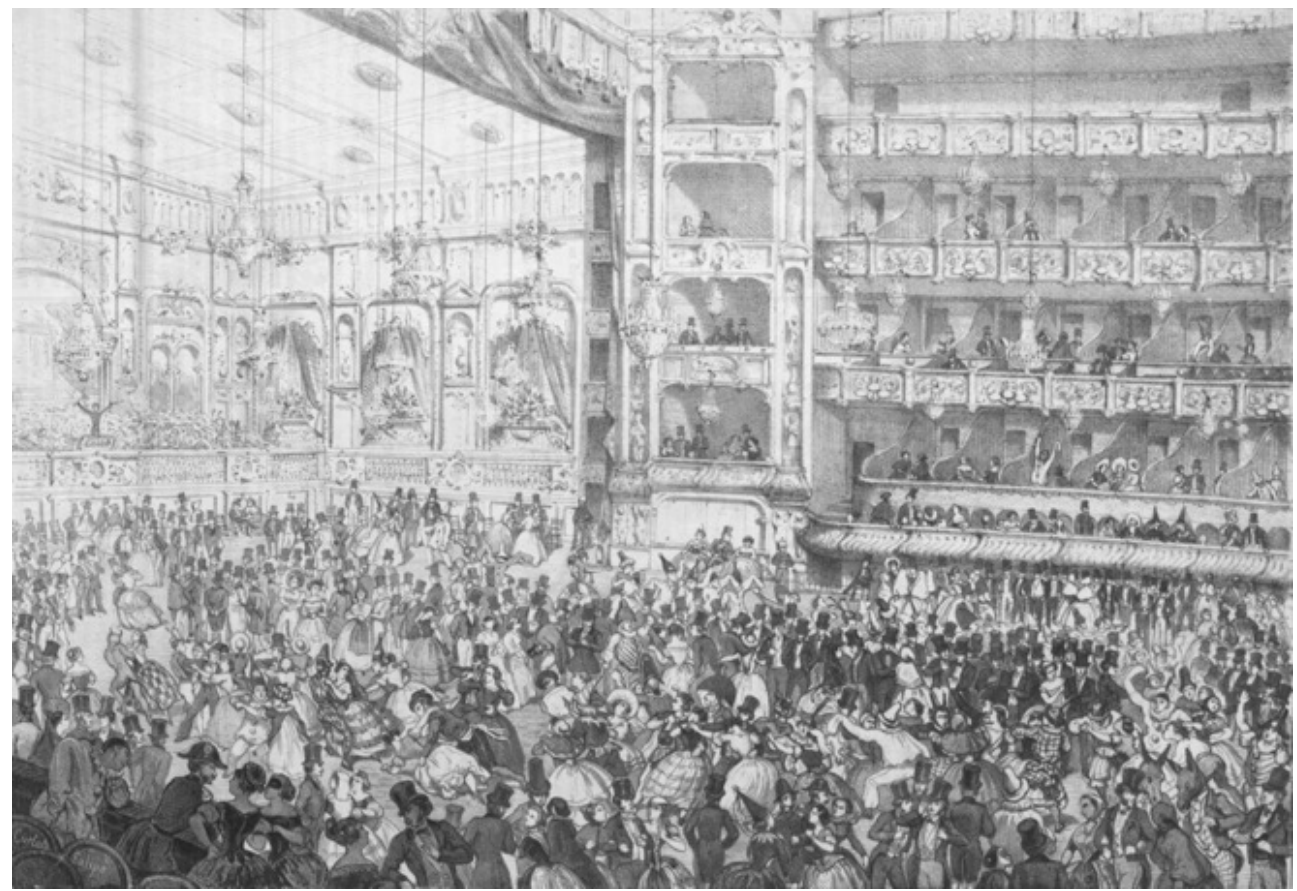

Figura 1. Interior del Gran Teatro del Liceo en un baile de máscaras. Fuente: La Ilustración Barcelonesa, 1 de febrero de 1858. Fuente: ARCA.

Y es en este tejido asociativo, como menciona Fontana (2015, p. 313), en donde se manifestaba «una cultura basada en la crítica de la sociedad existente, con una fuerte carga de antimilitarismo y anticlericalismo, y orientada hacia la conquista de las libertades en el marco de la república federal».

Además, hay que señalar, que la indeterminación del Estado liberal sobre la política educativa, como solución a la cuestión social, no sirvió para tejer un proceso de nacionalización que, por otra parte, apenas interesaba demasiado (Álvarez Junco, 2001; Fontana, 2015). El fracaso del siglo XIX no fue un fracaso de nacionalización, porque no había verdaderas intenciones de configurar ninguna nación. No había unión política, social o cultural para nacionalizar a contra naturaleza a un pueblo -dividido entre «dos Españas» (Figueroa, 1857, p. 2)- que el único enemigo que tenía era el propio poder gobernante de las castas eclesiásticas, aristocráticas, militares y caciquiles. Existía un pueblo hambriento analfabeto y sin escolarizar; un pueblo muy supersticioso, desconfiado y colérico, que solamente podía defenderse de los golpes de bastón de un liberalismo que no avanzaba hacia las libertades democráticas, porque tampoco las deseaba. Como apuntaba Jaime Balmes (1847), España no era una nación bien arreglada y en el trasfondo político de los sucesos escondía un problema social que impedía la nacionalización; se hacía pues imposible hacer la nación, sin antes arreglar la sociabilización y, para esto, había que 
deshacer la mentalidad de un estilo inquisitorial -dispositivo hispano osificado- de ejercer el poder, que fue mucho más allá de 1834 (Villacañas, 2017).

En Catalunya y especialmente en la burguesía barcelonesa subyacía el anhelo de una Constitución liberal, garantista de los derechos históricos; aun así, se criticaba la omnipresencia y el autoritarismo militar que forzaba a la nación catalana a un papel de colonia española (De Riquer, 2001) ${ }^{1}$. De todos modos, nadie pensaba en una Cataluña independiente de España. La Cataluña «industriosa, rica y civilizada» necesitaba más que nunca el mercado español, pero eso sí, bajo una gobernanza liberal, sin despotismo de monarcas y gobiernos atávicos:

Los ministros no conocen Cataluña. La civilización aquí está bastante adelantada: los catalanes son demasiado avisados para querer suicidarse: las ideas que aquí se desarrollan son diametralmente opuestas: lejos de reducirnos queremos ensancharnos: peleamos contra la aristocracia que el federalismo de cuatro provincias engendrara, fomentado por el espíritu de provincialismo. Ministros! Los catalanes no pueden estrecharse porque no caben ya en la esfera que les rodea, y mas bien que aislarse quisieran ensanchar el círculo: ¿sabéis el principio que prospera? El grande, el sublime, el de la fraternidad universal y asociación de los pueblos. Pensad que distancia hay de nuestra creencia á vuestros recelosos sueños. (El Constitucional, 1837, p. 2).

Además, en la Junta de Barcelona confluyeron verdaderos intereses democratizadores, liberales, progresistas y de entendimiento entre la pujante burguesía y un incipiente movimiento obrero que configuraba sus bases asociativas. En esta coyuntura se hilvanaba una corriente ideológica popular que se mostraba afín al republicanismo, al sufragio universal masculino, a la libertad de conciencia y de imprenta, a la desmilitarización y a la beneficencia social; conjunto de idas que expresaban una auténtica amenaza revolucionaria para el Estado, pero también para la poderosa burguesía catalana que no asumía la mediación de las condiciones de trabajo con las asociaciones obreras (Fontana, 2015).

A iniciativa Pedro Felipe Monlau, en 1841, se afirmó el lema: «¡Abajo las murallas!» que pretendía liberar a la ciudad «de esa faja que nos aprieta y nos ahoga que perjudica la salud pública y que ataja todos los intereses de esta ciudad de un modo considerable» (Monlau, 1843, p. 2456). Además, en esta iniciativa que fue apoyada unánimemente por el Ayuntamiento subyacía un telón de fondo: las murallas también eran las de la Ciudadela y las de una gobernanza centralizada que desde Madrid se hacía a hierro y fuego (Fontana, 2015). Por su parte, el influyente Jaume Balmes (1843) también pedía el derribo de las murallas y la Ciudadela para así ensanchar la ciudad con más porvenir de Europa.

${ }^{1}$ Aparte de la Constitución de Cádiz de 1812, en este período hubo tres Constituciones más $(1837,1845,1869)$. 
Por otro lado, la vida en Barcelona era un auténtico encarcelamiento intramuros. Las deficiencias higiénicas se acentuaban con el exceso de población que crecía rápidamente por una inmigración de gente joven del interior de Cataluña en busca de trabajo -jornaleros, tejedores, sirvientas, costureras, mozos de comercios- y mejores condiciones de vida (López Guallar, 2004).

Ahora bien, sobre este escenario actuaba la gobernanza de una política centralista y autoritaria que oprimía absurdamente la expansión industrial y comercial catalana -entonces la primera economía del país-. Ello también erosionaba a una clase trabajadora emergente, que además sucumbía como la principal víctima de las exaltaciones o intensas revueltas -bullangues- que se produjeron entre $1835 \mathrm{y}$ 1843. Cataluña no deseaba sentirse ni esclava, ni una colonia ocupada de España, y menos renunciar a sus signos culturales diferenciales (Arnabat, 2004; Cucurull, 1975) [Figura 2].

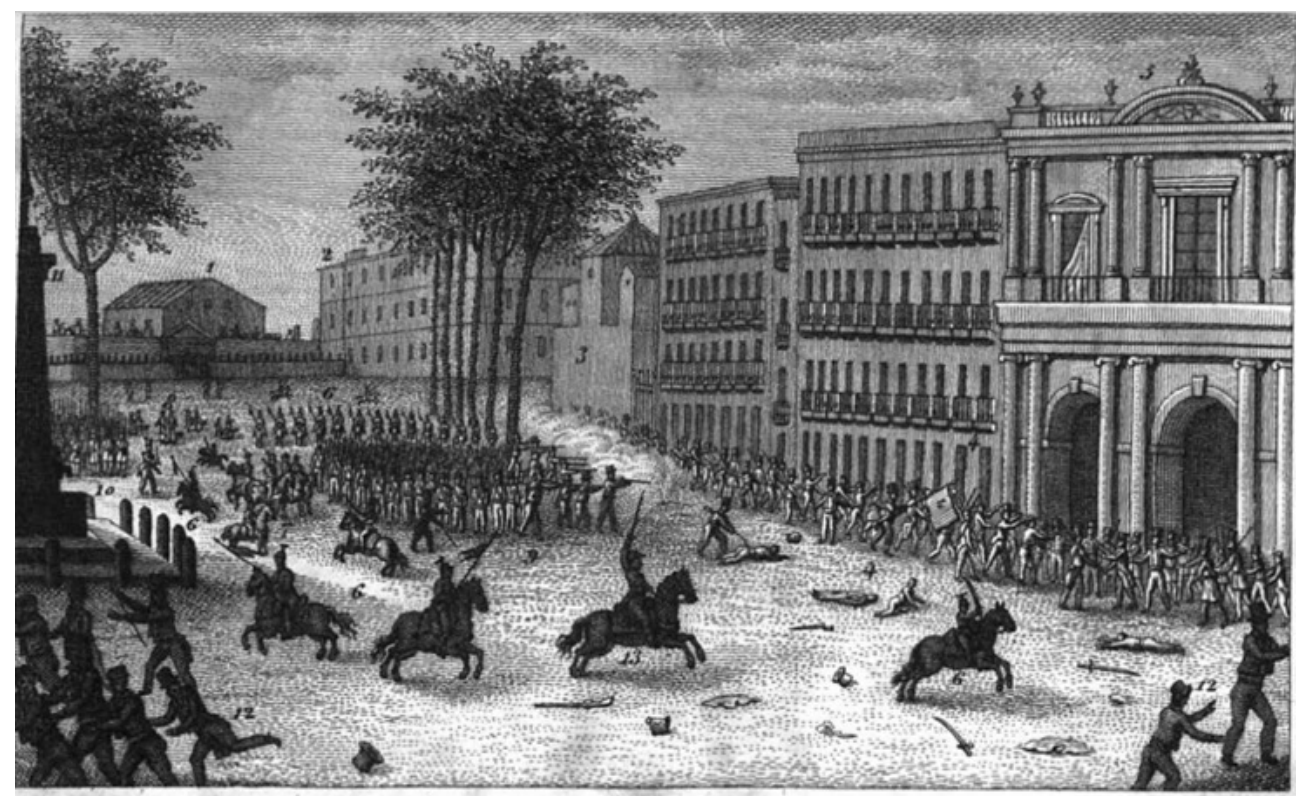

Tna horrorosa descarga hace palpitar aun los corazones insensibles.Bullangat"pasie

Figura 2. Escena de una de las bullangas de Barcelona (Del Castillo, 1837).

El 3 de diciembre de 1842, el Regente General Baldomero Espartero, «Duque de la Victoria», mandaba bombardear Barcelona desde el mismo Castillo de Montjuïc. Se decía que había que escarmentar definitivamente a los barceloneses rebeldes para restablecer el orden civil. Una masa de exaltados había iniciado una de las tantas revueltas de subsistencia moral de las clases populares, y para provocar al poder había iniciado el derribo simbólico de una parte de la muralla de la Ciudadela. 
Como ya es conocido, la irritación de los barceloneses a Espartero por mantener una política librecambista y acusado de beneficiar los intereses particulares con Inglaterra, principal rival comercial de los productos manufacturados catalanes, fue el detonante de su destitución definitiva del Gobierno español, pero el abuso del poder militar no cesó. En octubre y noviembre de 1843 Barcelona era nuevamente bombardeada por el Gobernador Militar Joan Prim en los sucesos de la llamada Jamància, la última bullanga popular de resistencia contra el poder despótico del Estado (Arnabat, 2004; Fontana, 2015).

Paralelamente, Jaume Balmes escribía El Criterio (1843, publicado en 1845); obra crucial en la que confrontó el «seny» catalán -el juicio de la razón o el sentido común-, epicentro de la renovación social y moral, con el grado de postración del país. Es decir, Balmes proponía mediar los conflictos sociales a través del "seny»; deseaba substituir el imperio de la ley y el clima de luchas violentas por la concordia y la paz social. De aquí que el modelo educativo de Balmes fuese, en adelante, un significativo referente para la Cataluña burguesa del siglo XIX (Vilanou, 2007, 2011).

Y es precisamente aquí, como apunta Villacañas (2017), cuando Balmes en La Sociedad (1843), reflejó la desproporción existente entre dos territorios -o provincias- y mentalidades, entre dos países -o naciones- (Cucurull, 1975). Barcelona, era pues una ciudad en la que reinaba un espíritu de trabajo emprendedor muy diferente al que había en otros puntos de España; una población que era vista como una nación extraña, sobre todo, «desde el punto de vista humano, social, económico y político» (Villacañas, 2017, p. 440). Barcelona -o Cataluña- era pues un modelo a seguir:

Al verla con sus numerosas fábricas, sus repletos almacenes, sus magníficas tiendas, sus elegantes edificios; al notar los hábitos de aseo en todas las clases; al observar el espíritu de trabajo y de adelanto que las domina, diríase que Barcelona no pertenece a España, sino que es una importación que se nos ha hecho de Bélgica o de Inglaterra, célebres por las cualidades que acabamos de enumerar. Nada se encuentra en ella que no contraste vivamente con la dejadez, la ociosidad, el desaseo que ofenden en otras poblaciones de la Península: todo allí es orden, regularidad, y cuanto indica un pueblo muy adelantado en los ramos industrial y mercantil y que hace cada día nuevos esfuerzos para progresar más y más en su prosperidad. (Balmes, 1843, p. 367).

Por otro lado, hay que destacar, como señalaba Balmes (1843), que las recientes revueltas en Cataluña, nada tenían que ver con las antiguas aspiraciones provincianas -nacionalistas- de independencia de España, sino que eran de índole nueva y muy moderna, y estaban relacionadas con la pujanza de las ideas que sacudían a otros países de Europa. Esta situación era especialmente visible en Barcelona, una ciudad cuya industria y comercio estaban en auge y que, a la sazón, conducía también a una mayor circulación y propaganda de las ideas -especialmente de las 
doctrinas socialistas de Roberto Owen- y del asentamiento de las modernas costumbres, mucho más que en ningún otro punto de la península.

Por su parte, Balmes (1843, p. 429) preocupado por el pauperismo de la ciudad pedía cuidar a la clase trabajadora: "hacerlos buenos y hacerles bien»; pedía a los amos no abusar de la autoridad y de la violencia, ponerse en la piel de sus empleados, pagar los salarios justos y mediar en los conflictos. Asimismo, aceptaba las asociaciones de trabajadores, siempre que no estuvieran alimentadas por una ideología política. Predicaba una solución asistencial y social con el fomento socorros mutuos, cajas de ahorros y otras instituciones para proteger a los obreros.

Ahora bien, en esta época ya se visibilizaba el miedo de las fuerzas vivas a un asociacionismo libre y revolucionario, sobre todo el miedo de la Iglesia. Además, las represarías de la última bullanga y la continua vigilancia a los conspiradores frenó los ambientes revolucionarios. Todo ello favorecía que las sociedades secretas y la francmasonería fueran el refugio para expresar y complicidades progresistas y democráticas (Arnabat, 2004).

Sin embargo, todo este ambiente fue muy propicio para que Barcelona se convirtiera en la puerta de entrada de las ideas radicales, socialistas y republicanas y, también, en el importante motor del clima de agitación social y política que se fue irradiando por todo el país (Moliner, 2016). Así también lo destacó Balmes:

En ningún punto de España se hallaba esa masa totalmente dispuesta a favor de las ideas revolucionarias como en Barcelona; en ninguna parte era tan fácil que los tribunos se viesen rodeados de un pueblo numeroso que secundara sus designios; en ningún punto existían a más de las clases inferiores, esa muchedumbre de artesanos que alucinados también por las ideas revolucionarias, favorecían más o menos directamente la propagación y los efectos de lo que, andando el tiempo les había de costar tantas pérdidas tanto malestar y sobresaltos. (Balmes, 1843, p. 389).

La época moderada (1844-1854) y la nueva constitución de 1845 ofreció una relativa tregua a los conflictos revolucionarios; eso sí, Cataluña estaba sumida en un estado de excepción permanente por las superioridades militares. A partir de entonces, el Estado organizó una administración mucho más centralista e implantó una gobernanza dura y represiva que satisfacía a los intereses burgueses. Por otro lado, el Estado concedió amplias prerrogativas educativas a la Iglesia y, en lo concerniente al ejército, si bien no mostró ningún interés para reformar sus instituciones, dejó mano libre para organizar un reclutamiento cuyo resultado conllevó la indecencia de atropellar a los más pobres (Fontana, 2015). La sombra del comunismo y de la revolución obrera corría por toda Europa y en España se intentaba refutar sus razones y minimizar el problema. Ahí están las aportaciones de Mariano Cubí y Soler (1852) o de Juan Mañé y Flaquer, traductor de la Historia del comunismo 
de Alfred Sudre (1856). Mariano Cubí $(1852$, p. 11) pronunciaba: «el comunismo como institución social, como sistema general de una nación, es de todo punto IMPOSIBLE». No obstante, por otra parte, las ideas federalistas y sociales eran también propagadas $\mathrm{y}$, desde estas posiciones, también se interpelaba a La regeneración de España (Ventosa, 1860), que pasaba por una federación ibérica y europea de naciones libres.

Así se expresaba, en el Eco de la Clase Obrera -9 de diciembre de 1855-, Joaquín Molar, uno de los Comisionados catalanes que, en Madrid, defendieron las demandas obreras, en relación con los sucesos de la huelga general y el bando del Capitán General Juan Zapatero -21 de junio de 1855- en suprimir las asociaciones obreras y en proclamar la ley marcial. Los obreros catalanes pedían fundamentalmente la libertad de asociación, pero Molar también añadía: "Los habitantes de Cataluña no quieren que les manden a palos, sino con la persuasión; y por eso me atrevo a decir que las autoridades no han tenido allí bastante tacto en las críticas circunstancias que hemos atravesado» (Benet y Martí, 1976, p. 280).

En Cataluña, el acelerado proceso industrialización estuvo acompañado por una penetrante etapa de conflictividad política, social, laboral e ideológica; situación que provocó una exclusión de la burguesía catalana en el liderazgo político español (De Riquer, 2001). Por otro lado, se acrecentó el clima de represión y de dominación militar sobre el orden público; en un estado de guerra permanente -las ejecuciones indiscriminadas sin procesos judiciales eran la normalidad de una actitud despótica e impune de los capitanes generales-, con lo cual, no solamente crecían las divergencias políticas, sino que se alimentaban movimientos revolucionarios populares, no exentos de una identificación nacional singular y creciente. A mediados del siglo XIX, las posiciones de Juan Mañé y Flaquer y de Manuel Durán y Bas denunciaban los abusos del poder sobre la situación catalana y pedían la descentralización administrativa del Estado (De Riquer, 2001).

En 1855 Juan Mañé se preguntaba ¿Qué es España?: «Establecer la unidad de España, es introducir la uniformidad y la igualdad de la miseria, de la ignorancia y del rebajamiento moral» (Mañé Flaquer, 1891, p. 100). De aquí, que también Mañé preguntase "¿Se quiere hacer con Cataluña lo que Inglaterra ha hecho con Irlanda?» (De Riquer, 2001, p. 141). Con ello pedía el cese definitivo del estado de excepción en el que se encontraba Cataluña que era mirada como una colonia española.

De todos modos, las huelgas de 1854, 1855 y 1856 fueron la reacción natural ante la prohibición de las sociedades obreras y sus demandas -mejora de salarios, de las condiciones higiénicas y la protección a la infancia- provocaron un clima que puso en crisis, una vez más, al Gobierno de Espartero (Benet y Martí, 1976). Las iniciativas subsidiarias privadas para fortalecer la convivencia ciudadana fueron el reflejo y resultado de una sociedad capitalista muy emprendedora, y no solo a nivel económico, sino también a nivel cultural, científico, recreativo y benéfico, situación que marcó significativas diferencias con el resto del país. 
La España liberal no supo contemplar las diferentes singularidades territoriales y culturales y forzó una construcción del país en provincias otorgando una unificación común artificial, pero bajo un Estado centralizado que no dudaba en ejercer la violencia para integrar a todas las nacionalidades históricas. Si bien, la nueva coyuntura estimuló la emergencia de nuevas resistencias de tipo cultural y distintivo -nacionales o catalanistas-, con el tiempo, la centralización del poder del Estado provocó la mirada de un «doble patriotismo» (Fradera, 2003, p. 59), como bien pudiera parecer en la singularidad de Juan Cortada (1805-1868) y su ensayo Cataluña y los catalanes (1860) y, en algunos otros más (Marfany, 2017). A nuestro juicio este doble patriotismo respondía accidentalmente a los intereses económicos y las relaciones de poder en juego personales, que en cualquier otra cosa. En cierto modo esta expresión ideológica fue fracturándose a raíz de los sucesos disyuntivos hasta alcanzar la organización del catalanismo político de principios del siglo $\mathrm{xx}$.

Aquí habría que añadir la invención de las guerras externas sin sentido, y cuyo objetivo solamente radicaba en elevar el honor y la gloria de unos generales ambiciosos e inquietos que buscaban ser recompensados con ascensos, títulos nobiliarios y posesiones. Así fue la chapucera guerra de África que, remozada de un fingido y forzado patriotismo, fue una caricatura del ultramontano y doctrinal racismo -neocatólico de «despertar entre las masas el odio a los infieles profesaban en otros tiempos» (Ventosa, 1860, p. 129)- de los mandatarios de la Iglesia (Fontana, 2015).

Con tantas guerras y levantamientos, el Estado liberal fue incapaz de encauzar el progreso del país, sin los incentivos de una política de industrialización frenados por unas mentalidades baturras acostumbradas a gobernar con modos autoritarios. En España no existió revolución liberal. Los poderes del Estado se negaban a ceder en la descentralización política y administrativa y solamente deseaban conquistar el poder. Señalar al respecto, que desde 1833 hasta 1875 los gobiernos apenas duraban un año.

A partir de 1856 la situación empeoró. A la crisis política sobrevino la crisis económica y la agitación turbulenta de una oposición progresista que demandaba ocupar el poder. La prohibición de las sociedades obreras, la explotación salarial, el abuso de las condiciones laborales y el encarecimiento de los productos básicos agudizó la supervivencia de las familias proletarias; todo un caldo de cultivo que fue aprovechado por los políticos y militares progresistas que, desde arriba, marcaron la hoja de ruta de un proceso revolucionario que lo único que pretendía era el apartar a los moderados y rectificar la orientación económica del país (Fontana, 2015). 


\section{SOBRE EL DISCURSO MEDULAR DE LA GIMNÁSTICA}

Antes que el Conde de Villalobos estableciera su gimnasio en Madrid, ya los había en Sevilla, Cádiz, Valencia, Figueras o Barcelona (Torrebadella, 2013b). Es precisamente esta última ciudad en donde la gimnástica moderna alcanzó un mayor grado de desarrollo y su embrionario estímulo surgió de las iniciativas gimnásticoeducativas patrióticas del Trienio Liberal. En este periodo los proyectos de Joaquín Català (1821) y el capitán Miguel Roth (1823), puede que sugestionadas por Buenaventura Carles Aribau (1820), ya profesaban incipientes transformaciones educativas en donde la educación física aparecía en el marco de una enseñanza general. Además, aquí también sobrevenía la influencia de Francisco de Amorós y Ondeano (1770-1848), refugiado político y gimnasiarca que en Francia culminó con la lúcida obra que había iniciado en la capital española en el Real Instituto Militar Pestalozziano (Fernández Sirvent, 2005; Sáenz-Rico, 1973; Torrebadella-Flix, 2015).

En estos años, en Barcelona se revelaba un fervoroso nacionalismo español (Marfany, 2017) y, en este contexto, la figura de Amorós era utilizada y divulgada patrióticamente (Fernández Sirvent, 2005). Especialmente, el Diario Constitucional de Barcelona ponía el acento en suscitar la polémica que subyacía sobre la figura de Amorós y su exilio político:

Las generaciones futuras que leerán la historia de nuestra gloriosa regeneración no podrán creer que un sabio de ideas libres comunique sus luces fuera de su patria, cuando ya debiera haber espirado la época de la proscripción junto con la del despotismo. Sin embargo, el decreto que detiene en algunas de nuestras provincias septentrionales a los españoles refugiados en Francia prolonga el llanto de innumerables familias, fomenta la desunión qué debiera evitarse, y priva la España de muchos sabios. (Noticias estranjeras [sic], 1820, p. 2).

Hay que destacar por eso, que tras la muerte de Fernando VII los reconocimientos personales a la obra de Amorós no fueron demasiado perceptibles, aunque puedan encontrase algunas alusiones. Una rareza es la referencia que aparece en el Diccionario histórico enciclopédico de Vicente Joaquín Bastús y Carrera (1795-1873):

y a pesar de la influencia que siempre ha tenido la educación física no solo sobre la suerte de los particulares, sino también sobra la de los estados, la gimnástica ha caído en total olvido porque los gobiernos nada han hecho para fomentar un arte cuyos resultados presentarían grandes ventajas a la sociedad.

Convencido de estas verdades importantes el célebre e ingenioso español Amorós, fundo en París en 1819 un establecimiento en el que se propuso desarrollar la fuerza física y la agilidad de los jóvenes; y el buen resultado que desde el momento experimento de las máquinas empleadas en esta instrucción, demostró lo que 
sucesivamente podía esperarse de este establecimiento semejante dirigido por un sabio tan inteligente. (Bastús, 1833, p. 50).

Aparte, fue especialmente significativo el reconocimiento que en 1839 Amorós recibió de su ciudad natal y que, a la sazón, posibilitó la creación del Gimnasio Civil en el Liceo de Valencia que él mismo organizó al regresar del exilio (Fernández Sirvent, 2005). Las noticias de este gimnasio fueron divulgadas también en la prensa de Barcelona y de Madrid (F. [El Corresponsal], 1839a, 1839b; Valencia, 16 de noviembre, 1839). A pesar del afecto de sus paisanos (Boix, 1848), Amorós nunca recibió un reconocimiento oficial y público por parte del Estado que restituyera el legado simbólico de su obra. Amorós regresó y murió en París el 8 de agosto de 1848, a los 77 años; todo parece que la prensa española no ofreció noticia alguna de su muerte.

No obstante, el legado gimnástico-educativo de Amorós se hacía visible (Monlau, 1840; Jullien,1840; Figuerola, 1841, 1844) en una Barcelona que emprendía un crucial empuje industrial y económico, del que dependía también el desarrollo de todo el país. Así, mientras la educación física y la gimnástica mostraban el alcance de su intervención regeneracionista y modernizadora, una Barcelona aún amurallada continuaba siendo desde 1714 una importante plaza militar y una ciudad tomada, con una Ciudadela que era símbolo de aquella derrota y dominación colonial borbónica y castellana.

En Madrid, mientras el Conde de Villalobos (1842) trataba de sostener una campaña patriótica de la gimnástica (Torrebadella, 2018)² y Julián Sainz del Río hablaba de las asociaciones gimnásticas alemanas ideadas para "conservar vivos y enérgicos los sentimientos de patriotismo y de nacionalidad» (Sainz [sic], 1842, p. 252), como ya hemos dicho, el "Duque de la Victoria», primero, y el año siguiente, el General Joan Prim, bombardeaban indiscriminadamente Barcelona. Luego, la época moderada (1844-1854) y la nueva constitución de 1845 puso una relativa tregua a los conflictos revolucionarios, eso sí, Cataluña estaba sumida en un estado de excepción permanente por las autoridades militares. En estos años, como ya hemos adelantado, la organización del Estado central se hizo más poderosa y concedió amplias prerrogativas educativas a la Iglesia y al estamento militar que además implantó un injusto reclutamiento que castigaba a los más pobres (Fontana, 2015). Por su parte, Villalobos en Madrid no tenía más atención que la de sus conciudadanos, y sus esperanzas de alcanzar un Gimnasio normal bajo protección del Estado quedaron desvanecidas (Torrebadella, 2013b).

Ya en este nuevo período, Monlau $(1846,1847)$ advertía sobre los preceptos higiénicos individuales y públicos y trataba de las ventajas de instalar gimnasios en todas las escuelas: "Muy importante fuera que a la par que en el aumento de escuelas primarias se pensase en el establecimiento de gimnasios. No faltan en las naciones cultas algunos modelos que imitar» (Monlau, 1846, p. 464): «Los gimnasios

\footnotetext{
${ }^{2}$ Para el Conde de Villalobos España era un Estado, un país, una nación y su patria.
} 
deben ser frecuentados con igual asiduidad que las escuelas o mejor dicho cada escuela habría de tener un gimnasio» (Monlau, 1847, p. 474). Y es aquí, en este desinterés político por la gimnástica al que se refiere Torrebadella (2013b), cuando también habría que visibilizar la ineficacia nacionalizadora del Estado que apuntan Álvarez Junco (2001) o De Riquer (2001).

En 1850 Barcelona disponía de 187.000 habitantes y su mayor parte correspondía a la muchedumbre obrera. El diario El Ancora mencionaba del "gran número de jóvenes que diariamente asisten a los gimnasios de esta capital» (Anoche asistimos..., 1851, p. 1). No obstante, estos usuarios del gimnasio pertenecían a las capas más acomodadas de la sociedad. Entonces, la gimnástica ya se ajustaba a diferentes finalidades y se podía diferenciar un alcance militar, higiénico, educativo, recreativo, ortopédico, terapéutico o artístico, y, por lo tanto, apareció una diversificación de gimnasios de diversa índole.

En torno a los beneficios curativitos de la gimnástica se destacaba el nuevo balneario de La Puda o baños termales a la orilla del río Llobregat de Esparraguera, al pie de la Montaña de Montserrat [Figura 3]. Estos fueron fundados por el doctor Antonio Pujadas Mayans (1812-1881), que junto a

la ortopédica y la gimnástica, estas dos partes del arte de curar que la una puede provenir en gran parte de la necesidad de la otra, apenas son conocidas entre nosotros, se ignora su benéfico influjo, cuando por otra parte vemos en París nuestro compatriota señor Amorós, que fundador y director del mejor establecimiento gimnástico, administra a nuestros vecinos los remedios preventivos de que carecen desgraciadamente sus compatriotas, y que los medios de curar y prevenir los pies torcidos, los principios de anquilosis por luxaciones, abultamiento de costillas, hernias etc.,: son los que nos proponen los fundadores de la compañía de las aguas de la Puda. (Diario de Barcelona, 1844b, pp. 4954-4055).

Así en este establecimiento, cuyos trabajos facultativos estuvieron a cargo de destacados médicos -Antonio Pujadas, Juan Buatista Foix, Antonio Coca, Manuel Arnús...- los baños y los ejercicios físicos fuera y dentro de las piscinas se incorporaron en las terapéuticas. Pero, además, en La Puda tenían cabida los «juegos gimnásticos, juegos indianos juegos acrobáticos, juegos físico-recreativos juegos... bailes domésticos y otras y otras diversiones que la moda y el capricho puedan inventar» (Arnús, 1853, p. 6).

Ahora bien, en Barcelona las murallas todavía permanecían en pie y los problemas sanitarios aumentaban. Estas no se derribaron hasta la llegada del Bienio Progresista 1854-1856, no obstante, la decisión final estuvo provocada al comprobar las dañinas consecuencias de la plaga de cólera de 1854 (Font, 1855; Presas, 1855). Para el año siguiente, la intervención de Pascual Madoz (1806-1870), gobernador civil de Barcelona, posibilitó el proyectó de ensanche, que fue finalmente aprobado en 1860 con el plan Cerdà. 


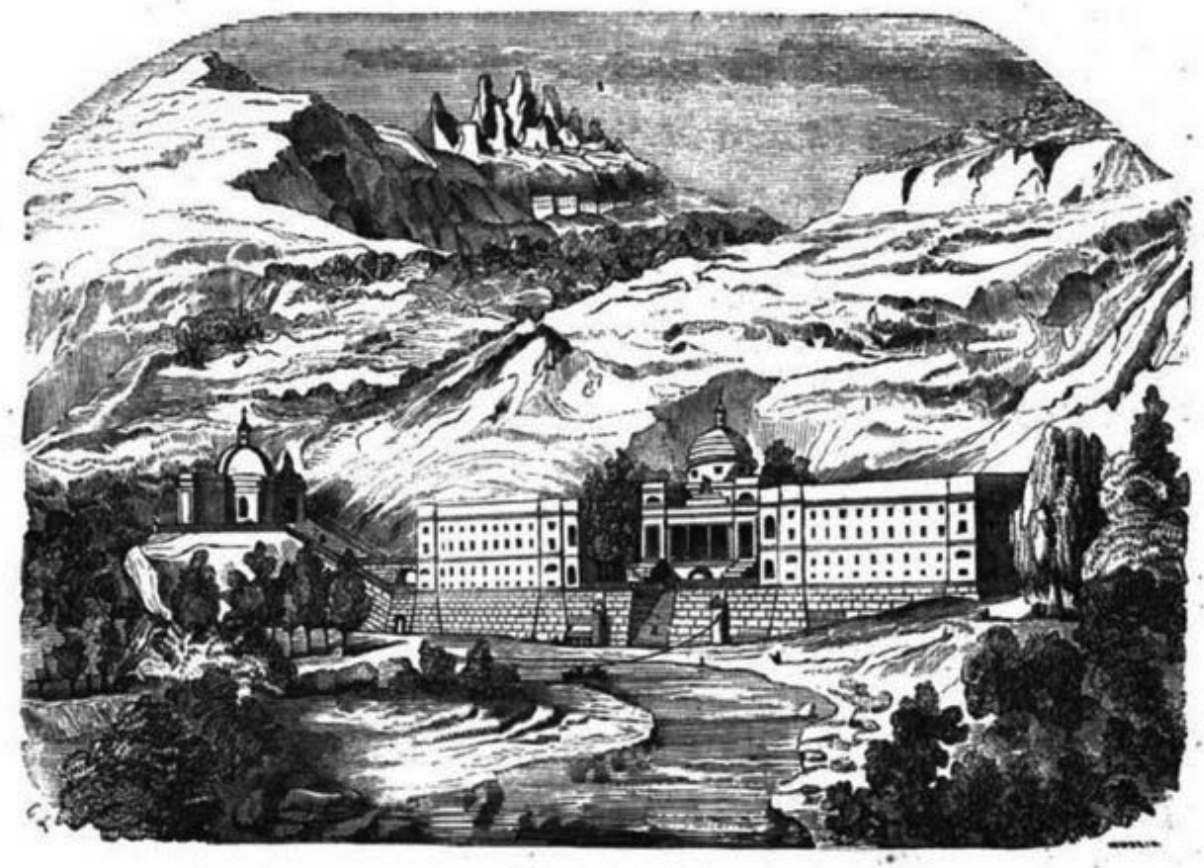

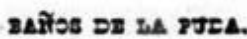

Figura 3. Baños de La Puda. Semanario Pintoresco Español, 26 de agosto de 1855, p. 265. Fuente: HBNE.

Por lo que respecta al plano físico-recreativo, ya en la década de los años cincuenta, la ciudad había instituido un sistema de prácticas burguesas que atendía las necesidades de ocio: baños de mar y de regatas, escuelas de equitación, salas de armas, salas de baile, salas de billar, y, también, los primeros gimnasios modernos (Torrebadella y Arrechea, 2015).

Hay que destacar que Barcelona fue una de las primeras ciudades aficionadas al juego de billar. Este era muy popular entre las clases acomodadas, pero estaba prohibido el jugar con apuestas. Los billares, aparte de las casas particulares de la sociedad distinguida, fueron colocándose en los cafés y en los círculos sociales... En Barcelona a mediados del siglo XIX existía el taller de Francisco Amorós, n. $83(1850,1856)$-luego en la calle San Pablo, 48- que proporcionaba mesas de gran calidad. Amorós decía ser el introductor del sistema de bandas de goma y único fabricante del ramo en España. Este escribió el Manual para los aficionados al juego de billar (1866) y otros libros en los que mostraba la calidad de las mesas que habían sido premiadas internacionalmente (Amorós, 1868). Una muestra por la atracción de este «gimnástico juego de billar» fue su incorporación en el lujoso Instituto Manicomio San Baudilio de Llobregat (1856, p. 453), que dirigía el mencionado Dr. Antonio Pujadas (1872) [Figura 4]. 
Instituto Maniconico de San Baudilio del Llobregat.

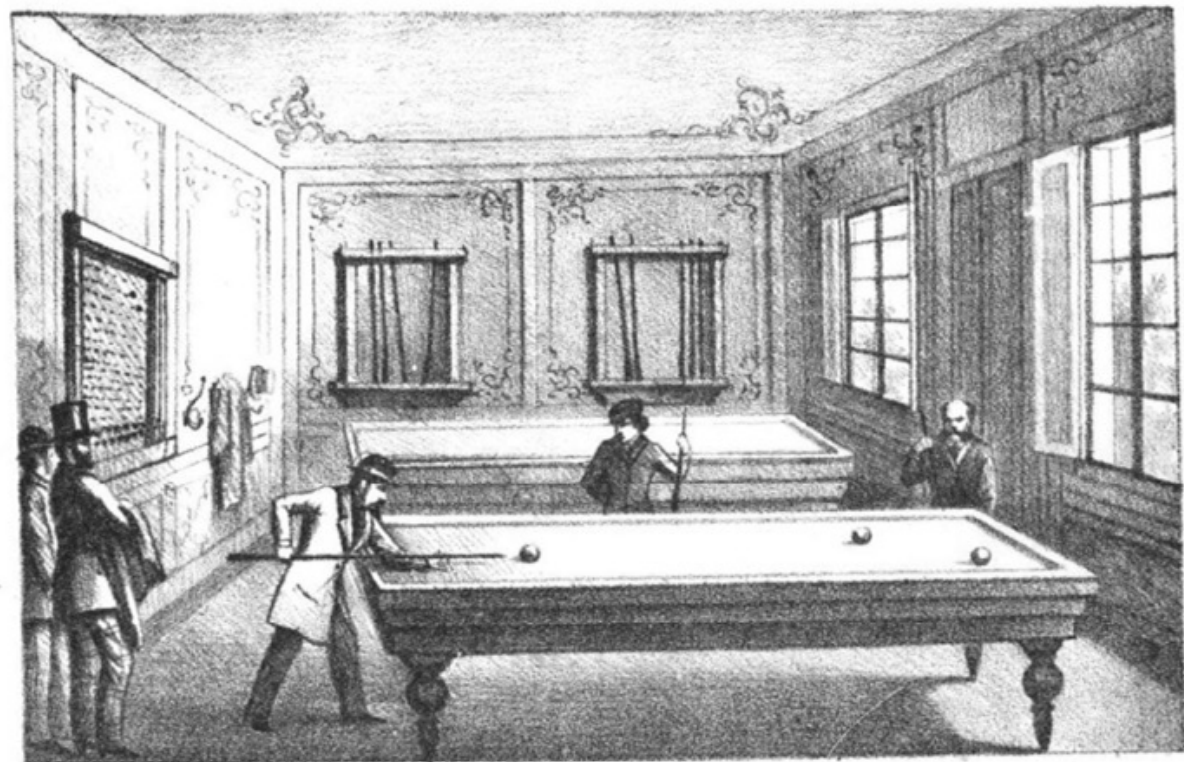

Sala de billares. para los Srẽs pensionistas distinguidos.

las demás secciones tienen igualmente sus billares.

Figura 4. Pujadas, A. (1872). El Manicomio de San Baudilio de Llobregat - Sucinta Historia de la Ciencia.. Barcelona: Imp. El «Porvenir» de la Viuda de Bassas.

Si bien Monlau (1847) puso como modelo el gimnasio que el Conde de Villalobos dirigió en uno de los mejores colegios de la Corte, la propaganda de este no se divulgó en Barcelona. No obstante, sí fue relevante el avance de los gimnasios higiénicos en Francia; entre estos el Gran Gimnasio de Triat o el Termo-gimnasio... del Dr. Braud:

Pero la gimnástica hermanada con la hidroterapia merece especialmente la atención, considerándola como medio preservativo de todas las enfermedades que afligen á nuestra pobre naturaleza. Formar hombres sanos y robustos, es regenerar la espacie humana.

Nadie duda que la gimnástica es cosa obligatoria en todos los colegios, en todas las escuelas y en todas partes donde los jóvenes, absorbidos por largos y penosos estudios, necesitan saludables ejercicios corporales. (Commentant, 1862, p. 10043). 
Se comentaba que la buena dirección de los ejercicios gimnásticos desarrollaba el instinto viril y la valentía. Así el ejercicio intenso y continuado -la caza, la natación, la esgrima, la equitación...- se prescribía para la contención de los apetitos y placeres venéreos, pero también para los hombres llamados de temperamento nervioso (Torrebadella-Flix y Vicente-Pedraz, 2016), "dotados de sensibilidad física muy viva y exaltada ordinariamente, y por una educación afeminada ya, por las habitudes de una vida sedentaria» (Debreyne, 1862, p. 211). El temperamento nervioso era considerado como "propio de un gran número de mujeres y de niños» (Debreyne, 1862, p. 213). En sí, se creaba el imaginario que en el género masculino se desprendía una enfermiza falta de valor, es decir, de cobardía y de pusilanimidad. De aquí que se prescribieran a los niños que desde la infancia se endurecieran con ejercicios gimnásticos «que inspiren un carácter varonil» (Londe, 1829, p. 134).

Por lo tanto, en los gimnasios del entorno urbano se configuró un paradigma romántico, un espacio en el que la juventud respondía a nuevas metáforas del cuerpo, en tanto que podían entrar a modelar y expresar corporalidades diferentes (Vicente-Pedraz, y Torrebadella-Flix, 2019). Barcelona reflejaba este paradigma moderno y diferencial; la ciudad había entrado en la época industrial, y los que asistían al gimnasio estaban acompañados de razones serias; sentían, como citaba Spencer, que en las «luchas industriales también la victoria es compañera del vigor físico de los productores» (Barbero-González, 2012, p. 591). Además, en estos gimnasios se concentró una clase social pudiente, de "gentes honradas» y que participó de la representación social que subyacía en este tipo de prácticas.

No obstante, en Europa, el asociacionismo gimnástico se enraizaba ideológicamente en la construcción de los emergentes nacionalismos modernos. Sobre este caldo de cultivo, en España subyacía una total indiferencia (Torrebadella, 2017). Así, por ejemplo, la fiesta gimnástica que celebró la Sociedad Gimnástica de Gubwiller -Alto Rhin- el 12 de mayo de 1861, con la participación de entidades suizas y alemanas [Figura 5], era una demostración del rápido desarrollo que iban a protagonizar las asociaciones gimnásticas en toda Europa:

Es imposible negar la utilidad de tales sociedades; al lado de las numerosas asociaciones literarias, corales y artísticas que existen y se proponen el perfeccionamiento intelectual y moral, es bueno que, haya otras cuyo objeto sea el desarrollo de la fuerza física y de la destreza: estas sociedades son el complemento de las primeras, y así se obtendrá lo que reclama el célebre Mens sana in corpore sano. Sería de desear que la idea fuese imitada en todas las naciones. (De Lasalle, 1861, p. 4). 


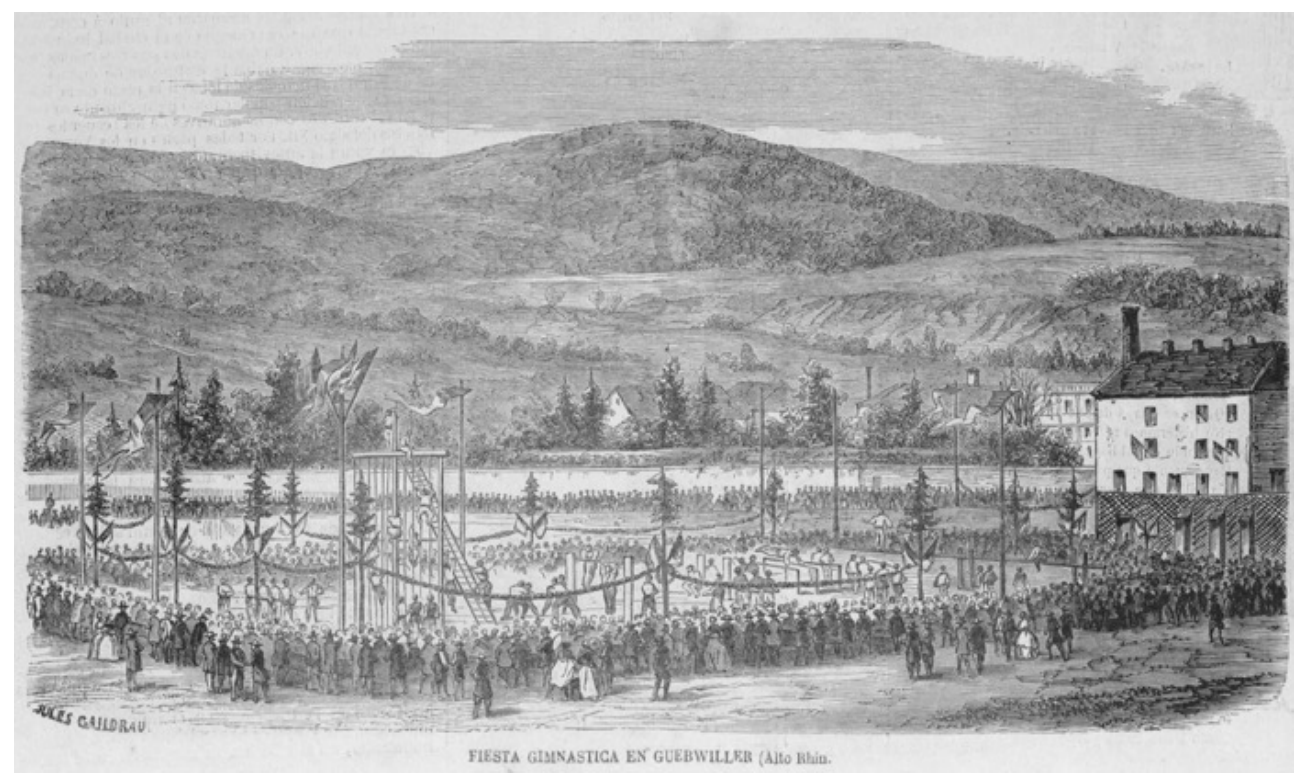

Figura 5. Fiesta Gimnástica en Gubwiller. El Correo de Ultramar, 1861, n.ㅇ 448, p. 4. Fuente: Biblioteca Virtual de la Prensa Histórica.

\section{SOBRE LOS PRIMEROS GIMNASIOS DE BARCELONA}

Hacia mediados del siglo XIX ya se habían instalado en Barcelona los primeros gimnasios ortopédicos -el de Pedro Font, en 1837, y el de Pablo Clausolles, en 1842- que trataban las deviaciones del raquis en las jóvenes (Torrebadella, 2011a; 2013c), pero también existían otros gimnasios destinados a la formación gimnástico-acrobática y a la gimnástica higiénica y recreativa (Torrebadella, 2013b, 2014b). Sin embargo, esta parte de la gimnástica no era muy conocida entre la población y, por otro lado, daba lugar a nuevas formas de negoció:

que la ortopédica y la gimnástica, estas dos partes del arte de curar que la una puede provenir en gran parte de la necesidad de la otra, apenas son conocidas entre nosotros, se ignora su benéfico influjo, cuando por otra parte vemos en París nuestro compatriota señor Amorós, que fundador y director del mejor establecimiento gimnástico, administra a nuestros vecinos los remedios preventivos de que carecen desgraciadamente sus compatriotas. (Barcelona, 1844, p. 4955).

Aparte, antes de llegar a la década de los años cincuenta se instalaron otros gimnasios en distinguidos centros educativos -en el Colegio de Carlos Carreras y el Instituto Barcelonés- (Torrebadella, 2013b). Asimismo, en 1844 se hablaba de «los 
señores socios y accionistas de Instituto Gimnástico Barcelonés» (Diario de Barcelona, 1844a, p. 1819) y, en 1845, de la Escuela de gimnástica militar dirigida por D. N. Barrios ${ }^{3}$, en la que acudían diariamente más de sesenta oficiales y todos los sargentos de la guarnición. Esta escuela se encontraba en Atarazanas, en el patio de ingenieros de San Agustín Viejo (Barcelona, 1845). Ahora bien, como veremos, los mejores gimnasiarcas de la ciudad -Bernabé Barrio, Carlos Berthier y Manuel Vall-, también ofrecieron sus servicios como profesores de gimnástica en otros colegios en los que no faltaron la oportuna instalación de gimnasios.

En aquel tiempo Barcelona era la capital de los espectáculos gimnásticos (Torrebadella, 2013a) y, pude decirse que en sus gimnasios se formaron destacados artistas que viajaron por toda España en las llamadas compañías gimnástico-acrobáticas (Dalmau, 1947). Entre estas escuelas de gimnástica hay que señalar la de Mr. Carlos Berthier ${ }^{4}$, un discípulo de Amorós que llegó a Barcelona a finales de 1846 y que muy pronto actuó en el Nuevo Circo Olímpico (1847) construido en el huerto del exconvento de los Capuchinos. Y si bien marchó durante un tiempo para trabajar en otros lugares de España, en junio de 1847 volvió a Barcelona. En enero de 1848 Berthier estableció una «Escuela de Gimnástica» en la c/ de Cirés, 5 travesía de la calle nueva a la Rambla (Bertier, 1848a). Por lo que se desprende del anuncio publicado en el Diario de Barcelona, este ya venía ejerciendo de profesor de gimnástica, pero ahora había mejorado el local, del que decía estar dispuesto para la enseñanza:

Escuela de Gimnástica. Mr. Bertier discípulo del coronel Amorós muy apreciado en esta ciudad por sus conocimientos gimnásticos, acaba de abrir un establecimiento donde los discípulos que concurrirán a sus lecciones recibirán una instrucción variada compuesta de ejercicios gimnásticos, luchas, manejo del palo y sable, trompadas, manejan el zapato, bastón a dos manos, etc. Estos diversos ejercicios desarrollan las fuerzas, dan agilidad, ligereza, y hoy día son el complementó indispensable, de la educación de los jóvenes en las principales ciudades de Francia e Inglaterra en que los grandes establecimientos de instrucción tienen un gimnasio completo. Dicho señor Bertier puede presentar en su abono multitud de discípulos que ha formado en esta capital y espera que Barcelona reconocerá la utilidad del establecimiento que desde ahora está perfectamente dispuesto... (Bertier, 1848a, p. 334).

Hacia finales de este año Berthier fue nombrado profesor del Gimnasio del Instituto Barcelonés, lugar en el que también impartió clases a otros clientes (Bertier,

3 También aparece citado con el nombre de Francisco Barrios o Bernabé Barrio, profesor que fue del Instituto de Segunda enseñanza de Figueras (Gerona).

${ }^{4}$ En la prensa de la época puede encontrarse este nombre escrito en diferentes formas: Berthier, Bertier, Bertié. Dalmau (1947) habla de Julien Bertier. Hay que apuntar que este profesor se hacía llamar también con otro nombre que aparece escrito de distintas maneras: Dassevelle, Dasseville, Dassevill o Dasserville. 
1848b) y, además, "considerando que la natación es una de las partes más interesantes de la gimnástica y tal vez la más importante y necesaria a todas las clases de la sociedad», este gimnasiarca estableció unos cursos para aprender a nadar (Dassevelle, 1848, p. 3913).

Asimismo, Berthier continuó durante varios años trabajando en actuaciones públicas -Teatro Nuevo, Plaza de Toros, Teatro Principal, Circo Barcelonés...- y demostrando sus habilidades gimnástico-acrobáticas y especialmente en el uso del trapecio, con lo cual, aparte de acreditarse como excelente profesor, intervenía en la promoción de la gimnástica artística y ello provocaba que muchos gimnastas se formasen en su escuela.

En aquella época, los peligros de este tipo de gimnástica podían ocasionar percances bastante graves. Tanto era así, que Berthier tuvo que defenderse ante los falsos rumores que sostenían que un joven había perecido en un accidente debido al descuido del profesor (Dassevill, 1848).

En 1851 el gimnasio de Berthier se conocía con el nombre de Gimnasio Civil y Militar, pero también Berthier era conocido por C. Dasseville (1851). En este año ya ejercía de profesor de gimnasia en el cuerpo de Bomberos, coincidiendo con el arquitecto y urbanista Antonio Rovira y Trias (1816-1889), que era director jefe de la Compañía de Bomberos de Barcelona -en 1848 ya ejercía de jefe, pero no fue director hasta 1853-. Antonio Rovira (1856) consideraba imprescindible el establecimiento de gimnasios aptos para la preparación de los bomberos (Rovira, 1856).

En 1853, María de la Asunción Berthier, esposa de Carlos Berthier, abrió un gimnasio especial para señoritas en la c/ del Mediodía, 9 en donde atendía una gimnástica ortopédica; y también ofrecía lecciones en las casas particulares de las discípulas. Por su parte, Mr. Berthier (1853) continuaba ofreciendo clases de gimnástica y esgrima de palo, sable y florete. Los discípulos de Berthier solían representar exhibiciones públicas de gimnástica y de asalto de armas; el Teatro Circo Barcelonés era uno de los puntos escogidos. En estas representaciones también participaba la Sra. Berthier que hacía números de bailes, entre estos el de la "Gitana andaluza» (Bertier, 1854).

En abril de 1855 Berthier inició un viaje por el extranjero para perfeccionar estudios profesionales y de regreso a Barcelona, en 1858, volvió a sus actividades como profesor de gimnástica y de armas. Según él, llevaba 21 años ejerciendo de profesor (Berthier, 1858). En 1860 abrió el Gimnasio Ortopédico Normal Barcelonés, c/ Ramalleras, 16 y atendía «a cuantas personas se vean imposibilitadas por algún defecto físico, su pronta y radical recuperación» y, además, procuraba «horas de enseñanza curativa para señoras» (Bertier, 1860, p. 2699) [Figura 6]. El establecimiento contaba con los mejores adelantos de la época y estaba abierto a todos los facultativos médicos de la ciudad para que emitieran informes favorables de su buena disposición y dirección. 


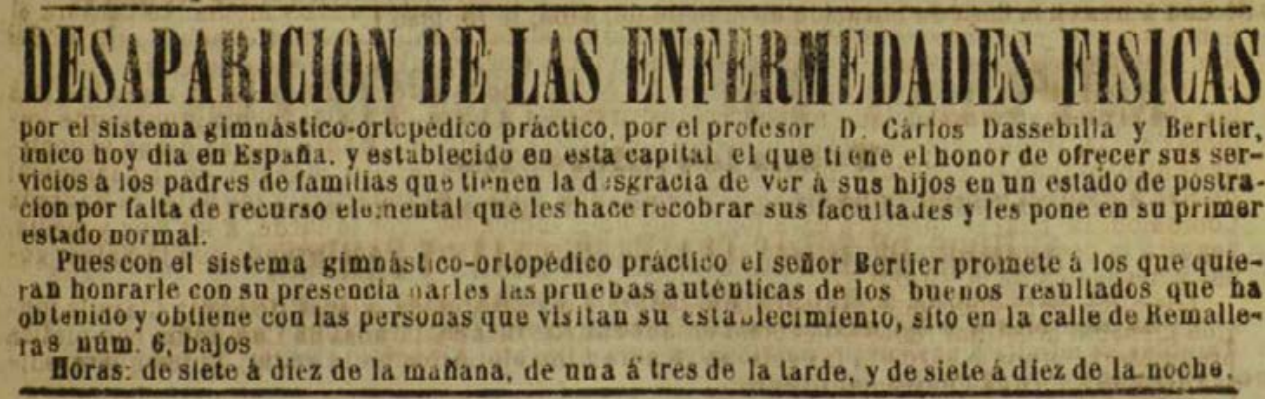

Figura 6. Anuncio gimnasio Bertier. Diario de Barcelona, 17 de marzo de 1860, p. 2615. Fuente: ARCA

Ahora bien, el gimnasio de Berthier no era el único que había en Barcelona. En la ciudad había otros profesionales que también se dedicaban al oficio de reparar la salud a través del ejercicio físico. Entre estos se encontraban, el profesor de baile Antonio Biosca y, también, Eudaldo Thomase (1783-1868), un maestro de esgrima francés, que desde 1814 dispuso de varias salas de armas, en donde aparte de las clases de esgrima, también se organizaban veladas de asaltos. Thomase publicó el Tratado de esgrima a pie y a caballo (1823) y consideraba la práctica del florete como la parte más interesante de la gimnástica. Así recomendaba su ejercicio a los que padecían determinadas enfermedades para recobrar la salud, tanto para hombres como señoritas (Thomase, 1851, p. 7118). En 1853 disponía de una Academia de armas en la Puerta de Santa Madrona, 20, lugar en el que trató la esgrima desde un enfoque higiénico-médico: "para conservar el cuerpo ágil y fuerte, que da flexibilidad a todos los órganos, retarda la vejez de muchos años, es muy bueno contra las enfermedades nerviosas, y sobre todo para los que padecen del pecho" (Thomase, 1853, p. 4302). En 1857 Thomase, con 41 años de experiencia práctica en Barcelona, daba inicio a un significativo giro conceptual ofreciendo la «gimnástica higiénica aplicada a la infancia de ambos sexos, sin aparatos, solo con movimientos y ejercicios convenientes a cada uno... con la ayuda de su hija, y el acreditado y muy conocido profesor don Antonio Biosca» (Thomase, 1857, p. 9707). Thomase estuvo activo hasta 1868, año en el que murió con 85 años.

Otros profesores de gimnástica fueron los hermanos José y Manuel Vall Cardona. Según Dalmau (1947, p. 45), en 1845 Manuel Vall ya disponía de una «escuela de gimnástica» en la c/ Puente de la Parra. En este gimnasio Manuel Vall realizaba "sorprendentes equilibrios y otras suertes de agilidad y de fuerza» que eran de gran admiración (Vall, 1850, p. 3824). Pero ambos hermanos provenían de la gimnástica funambulesca. En el Teatro Principal, «el acreditado maestro de gimnástica» José Vall ejecutaba arriesgados ejercicios en el trapecio $y$, por su parte, Manuel Vall realizaba "con seguridad y destreza varios y difíciles ejercicios de equilibrio sobre la bola, los que le han merecido los mayores elogios en cuantos teatros del extranjero» (Teatro Principal, 1852, p. 1). Más tarde, José Vall enseñanza gimnasia 
en la c/ de la Avellana, 5 en clases de 8 a 9 de la mañana y en las mismas horas de costumbre (Vall, 1854) ${ }^{5}$ [Figura 7].

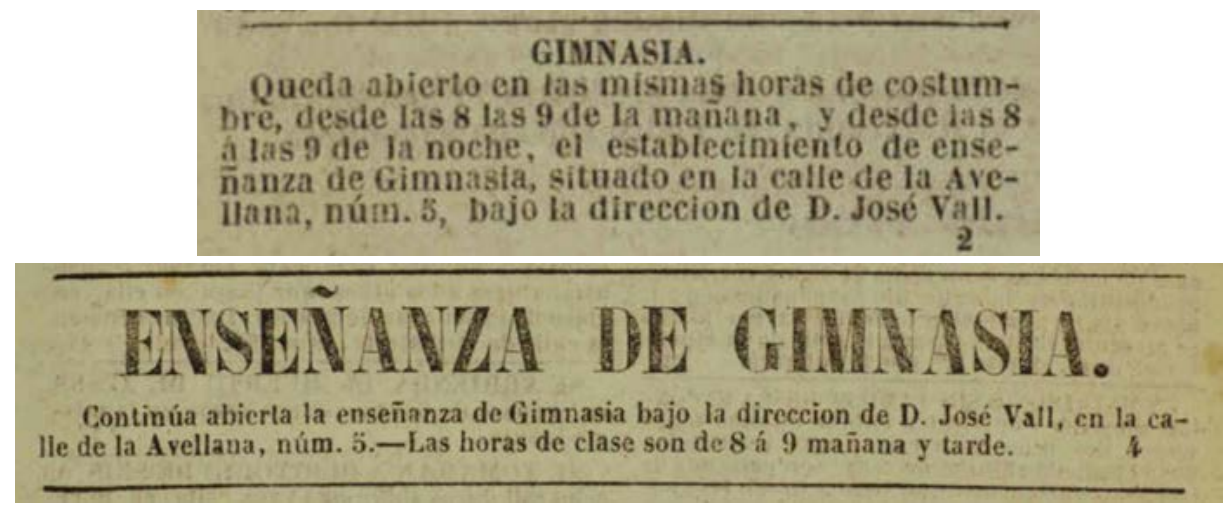

Figura 7. Diario de Barcelona, 10 de octubre de 1854, p. 7082. Diario de Barcelona, 27 de octubre de 1854, p. 7535. Fuente: ARCA.

En el periódico El Barcelonés, un artículo que versaba sobre la educación física, recomendaba el ejercicio de la gimnasia, que con tanto mérito había desarrollado Francisco Amorós al restablecer este arte en la época actual. Terminaba este artículo manifestando que Manuel Vall había alcanzado en «dicho arte y sistema un profundo estudio, añadiendo a este el de la medicina y anatomía en su aplicación, bajo cuyos auspicios tiene abierto un pequeño, pero bien dirigido gimnasio en esta ciudad, calle del Puente de la Parra» y, por esta razón se recomendaba este establecimiento a los aficionados (Barcelona, 1850, p. 6850). Manuel Vall era un profesor de gimnasia muy apreciado que había impartido clases en el Instituto de Tarragona y en el Colegio Real de Valencia y, en Barcelona, daba clases en importantes colegios, es decir, tenía numerosos discípulos de clase distinguida (Barcelona, 1855).

La labor iniciada por Francisco Barrios en Escuela de Gimnástica Militar continuó. En 1851 el gimnasio pasó a ser dirigido por Juan Moreno y Manso, el segundo comandante del Regimiento de Infantería Astorga 44 (Torrebadella, 2012a). En la Academia de Medicina Militar de Barcelona (1851) existía una verdadera preocupación por la higiene, la alimentación y los ejercicios más adecuados para las tropas, que no eran precisamente aquellos ejercicios de adorno y acrobáticos que se exhibían públicamente (Barcelona, 1851). Hay que resaltar que muchos barceloneses tuvieron el primer contacto con la gimnástica durante el servicio militar. De aquí que Joaquín Bosch, Viceconsultor supernumerario, Primer ayudante médico efectivo del Cuerpo de Sanidad Militar mostrase su preocupación por asistir a los reclutas con una adecuada educación física (Bosch, 1851).

${ }^{5}$ En 1853 José Vall era profesor de gimnasia en el Instituto de Tarragona. «Tarragona, 1 de setiembre de 1853», Diario de Barcelona, 5 de septiembre de 1853, p. 6252. 
Como vamos comprobando, la tesis de Torrebadella (2013a) que relaciona la gimnástica funambulesca con los gimnasios higiénicos va cobrando aún más relevancia. Prueba de ello es la trascendencia de este tipo de ejercicios, cuyo dominio proporcionaba una fácil salida profesional para muchos jóvenes intrépidos y con ganas de conocer mundo. Una de las compañías circenses que afirman el impulso del momento fue la Joaquín Batlle, que en 1854 actuaba en los Campos Elíseos (1854) con la participación de jóvenes - gimnastas y clowns-y cuyos apellidos indican claramente su procedencia catalana: Rexach, Jener, March o Batlle. Entre estos también se encontraba el joven Nicolás Camús, quien al cabo de poco dispuso de una compañía propia y, años más tarde, hacia 1880, compró el antiguo Gimnasio

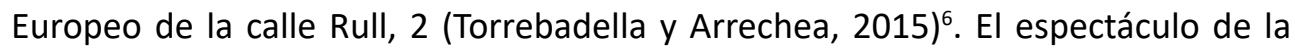
compañía de Joaquín Batlle estaba amenizado por la orquesta de Gaspar Agut.

Por otro lado, hay que destacar aquí, la influencia que el cuerpo médico estaba ejerciendo en la comunidad. El 23 de marzo de 1851 en la Sociedad Barcelonesa de Amigos de la Instrucción, el socio doctor leridano Luis Gonzaga Roca Florejachs (1830-1882) leía una memoria sobre la «Utilidad de la gimnástica en sus aplicaciones a la ciencia médica y a la educación de los pueblos» (Cots, 1851, p. 12). Ahora bien, por otro lado, la obra de Miguel Arañó (1852) aconsejaba a los padres sobre los riesgos de la mala educación física que podían recibir los niños que asistían a los gimnasios de la ciudad.

Pero, además, en esta época, significativos tratados de terapéutica se hacían eco de las aplicaciones gimnásticas, y la mayoría no olvidaron la deferencia de mencionar la obra de Amorós (Vicente-Pedraz y Torrebadella-Flix, 2017). Entre estos tratados de terapéutica publicados en Barcelona se encuentran los de Pons (1850), Foix (1858), Coca (1862) y, además, también se publicaba -en Madrid- la obra del doctor Sebastián Busqué y Torró Gimnástica higiénica, médica y ortopédica o el ejercicio considerado como medio terapéutico (1865), que daba a conocer las particularidades del método del profesor Alfonso Vignolles, en su acreditado gimnasio de la Corte (Torrebadella-Flix, Rivero-Herraiz y Sánchez-García, 2019).

Efectivamente, durante la década de los años sesenta la gimnástica empezaba a ser muy valorada en el ámbito médico y las revistas profesionales divulgan las ventajas terapéuticas por todo el país. Asimismo, en la Facultad de Medicina se presentaron reveladoras tesis doctorales sobre la utilidad de la gimnástica (Torrebadella, 2012c, 2014). Y, si bien las indicaciones atendían preferentemente al sexo masculino, cada vez aparecían más observaciones sobre la maltratada educación física femenina (Torrebadella, 2011), con lo cual, el gimnasio se presentaba como solución a los males y enfermedades que consumían al sexo femenino (Torrebadella-Flix, 2020b):

${ }^{6}$ «Ha fallecido don Nicolás Camús, notable funámbulo que había llamado la atención años atrás en Barcelona y otras capitales, y dueño últimamente del gran Gimnasio que lleva su nombre, instalado en la calle de Rull». La Vanguardia, 27 de agosto de 1887, p. 5. 
En España misma hay algunos, y sin ir más lejos, en Barcelona, por los años 1855, se establecieron dos gimnasios, uno para mujeres y otro para hombres, dirigidos por hermana y hermano respectivamente, de los que vimos salir jóvenes de ambos sexos, algunos de los cuales al entrar llevaban la muerte escrita en los semblantes, y a la vuelta de un par de años, robustos, ágiles y respirando salud, estaban completamente transformados. Una señorita, hija de las principales familias de comercio de aquella capital, desahuciada por famosos médicos a causa del raquitismo tan excesivo que dominaba su constitución orgánica, emprendió el curso y a los tres años, salvada del grave peligro que amagaba su existencia, era una de las bellezas más esbeltas que paseaban las calles de la capital del principado. Este solo ejemplo prueba hasta donde alcanzan los beneficios de la gimnasia empleado en la educación física (De Fabregues, 1868, pp. 337-338).

El «Gimnasio higiénico y recreativo» de Juan Estrany también fue un establecimiento muy conocido en la época. Este profesor impartía clases de gimnasia en los principales colegios privados de la ciudad y, después de Nicolás Camús, fue el instructor del cuerpo de Bomberos. En noviembre de 1857 Estrany se establecía por cuenta propia en un local de la Plaza Beato Oriol, 4.

Estrany $(1857$, p. 9299) aprovechaba entonces, según sus propias palabras, la oportunidad que ofrecía el momento, puesto que en España se estaba evidenciando una generalización de la gimnástica: "de modo que en el día se enseña en cuasi todos los colegios, en los cuerpos del ejército, y muchos padres de familia procuran que sus hijos se dediquen a tan útil estudio». Por otro lado, Estrany proponía una intervención higiénico-médica y presentaba una gimnástica metódica, con ejercicios bien graduados y dirigidos para mantener y fortificar la salud e inclusive para prevenir y curar algunas enfermedades.

En 1862 con quince años de práctica a sus espaldas, Estrany decía haber visitado los mejores gimnasios del extranjero y tener a su cargo las clases de varios colegios de la capital. Estrany era asiduo a presentar exhibiciones públicas de sus alumnos en los teatros. Estas actuaciones tenían el objetivo de mostrar el buen método de enseñanza utilizado (Barcelona, 1862) y «demostrar a los padres y deudos de los discípulos de la mayor parte de colegios de esta ciudad, los adelantos de aquellos en el difícil y arriesgado arte gimnástico» (Gacetillas, 1864, p. 1). Además, se anunciaba frecuentemente en la prensa mostrándose a disposición de servir de profesor «en tratos convencionales y ventajosos con los señores directores de colegios» (Estrany, 1862, p. 9939). Estrany solía también practicar ejercicios con sus alumnos en el Paseo de San Juan, todos los domingos por la mañana (Miret, 1931). En 1868 Estrany decía tener «20 años de estudio de la gimnástica del coronel Amorós, marques de Sotelo» y se comentaba que «la gimnástica bajo su dirección viene a ser un conjunto de medios de terapéutica, al mismo tiempo que un arte recreativo y un sistema de educación física» (Estrany, 1868, p. 5682). Hacia 1872 se trasladó a un local más espacioso e higiénico en la calle Canuda, 31, donde continuaría su labor como gimnasiarca hasta su muerte en 1887 [Figura 8]. 


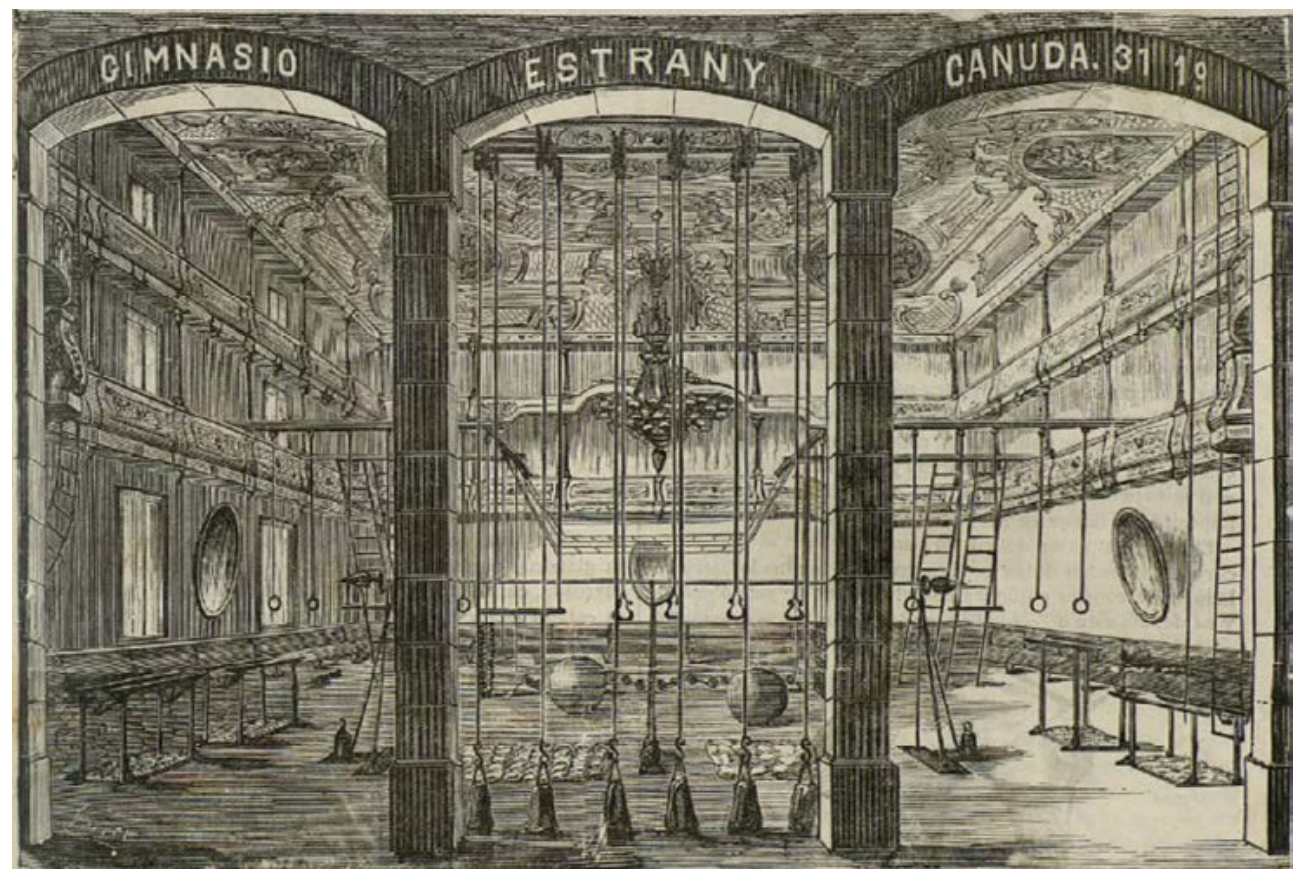

Figura 8. Revista Universal Ilustrada, 17 de marzo, 1879, n‥ 10, portada. Fuente: Universitat Autónoma de Barcelona.

Por lo tanto, comprobamos que antes de la década de los sesenta, la ciudad contaba con significativos gimnasios en donde el ejercicio higiénico y recreativo tomaba especial consideración entre el elemento joven de la buena sociedad. Así, en 1857 existía una Academia de gimnástica, en la c/ Rull frente a la c/ Obradores, y se decía que estaba muy concurrida (Gimnástica, 1857). Este gimnasio era otra iniciativa del veterano profesor Juan Vall.

Así se puede considerar que las iniciativas de nuevos establecimientos, sin duda alguna, se prestaban como atractivos negocios, como ya estaba sucediendo en otras ciudades de Europa:

Parece que se abrirá una nueva academia de gimnástica bajo la dirección de un discípulo del señor Barrios, director de los principales gimnasios de la corte, y el que comenzó esta enseñanza en Barcelona, hace años, en el Instituto Barcelonés; dícese que se trata de establecer unidas, la gimnasia y la equitación: de ambas enseñanzas hay pocos establecimientos en Barcelona, comparados con los que tienen otras ciudades del extranjero donde es más reducida 1a población. (Gimnástica, 1858, p. 7). 
También en la c/ del Mediodía, 9, en una cuadra en donde antes se encontraba el gimnasio de la señora Berthier ${ }^{7}$, un grupo de jóvenes se estableció por cuenta propia. En este nuevo proyecto probablemente se encontraban Joaquín Ramis y Florencio Quadras (Balius, 1985), que además disponían del apoyo de Alfonso Vignolles que introducía las primeras clases de pugilato -o de boxa francesa-. Al respecto se mencionaba: "la enseñanza de este ejercicio está recomendada para robustecer el sistema muscular, y se nos ha elogiado por personas competentes el buen método que observa el citado maestro» (Barcelona, 1858, p. 5157).

El 11 de abril de 1859 Antonio Moratones Freixa, un antiguo gimnasta que en 1842 ya actuaba en una reconocida compañía gimnástica (Patio de las Magdalenas, 1842), ponía al servicio de la sociedad barcelonesa un gimnasio dirigido a coadyuvar a «la salud, la prolongación de la vida y el mejoramiento de la especie humana». Así, el gimnasio de Moratones, aparte de la gimnástica higiénica y médica, por 40 reales al mes, también se podían «aprender figuras de adorno» [Figura 9]. Asimismo, hay que destacar, como ya harían prácticamente todos los gimnasios, clases especiales para señoritas, "las que desea el director vayan acompañadas de sus padres o tutores» (Moratones, 1859a, p. 3842).

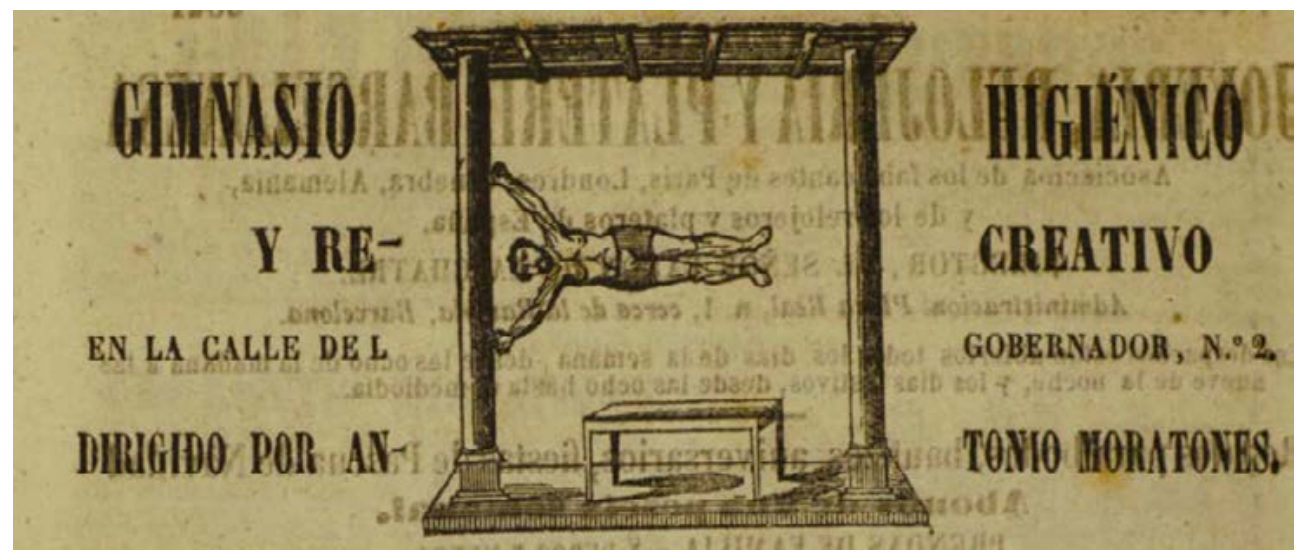

Figura 9. Gimnasio higiénico recreativo. Diario de Barcelona, 8 de abril, de 1859, p. 3842. Fuente: ARCA.

Del mismo modo que el profesor Berthier, al llegar el verano Moratones (1859b) se ofreció para organizar clases de natación teóricas y prácticas para todo tipo de personas, pero especialmente a la profesión militar [Figura 10].

${ }^{7}$ Anuncio de alquileres: «En el piso bajo de la casa núm. 9 de la calle del Mediodía», Diario de Barcelona, 4 de febrero de 1854, p. 863. 


\section{NATACION.}

Aceroándose la temporada de baños, pongo en conocimiento del publico, que en mi gimnasia de la calle del Gobernador, n. 2 , desce hoy en adelante daré lecciones de natacion á los que deseen aprender tan ntil arte, pues que nadie ignora los buenos resultados que puede dar al Estado y a la humanidad el saber nadar; omito reseflar sus utilidades y tan solo me concreto à decir que es de suma utilidad à toda clase de personas y en particular à los que se dedican a la carrera militar, etc.

Las horas de clase son por ahora de ocho à diez por la noche, y si se reuniesen unos cuantos, tambien las daré do dia, à la hora que se convengan.-Este, su afectisimo, Antonio Moratopes.

Nota. - La enseñanza teórica será en el local arriba espresado y la práctica en el mar, donde habrà el sufieiente numero de lanchas de ausilio.

Figura 10. Natación. Diario de Barcelona, 7 de junio de 1859, p. 6123.

En 1862 Moratones se anunciaba con el título de "Gimnasio Higiénico y Curativo» y se identificaba como profesor e instructor del ejército; ofrecía clases para señoritos, caballeros, señoritas y «señoras enfermas y defectuosas» (Moratones, 1862, p. 8677). Un año después, se trasladó a la c/ Mercaders y en Ronda Universidad, 25.

Hay que destacar que Moratones fue un magnífico gimnástica acróbata, pero cuya formación empírica fue a cargo del profesor José Florencio Quadras ${ }^{8}$ y, según Dalmau (1947), tenía una fuerza fuera de lo normal. Moratones adquirió reconocimiento con el tratado Nociones elementales de gimnasia para uso de los jóvenes de ambos sexos en el que transcribía la gimnástica de Francisco Amorós (Moratones, 1863); fue la primera obra gimnástica publicada en Barcelona.

A primeros de 1859 actuaba en los circos y teatros de Barcelona -Circo Barcelonés, Circo Real, Campos Elíseos...- el «barcelonés» Juan Milá, «principal gimnasta del Hipódromo de París», el cual se comparaba en el trapecio al mismo Jules Leotard (1838-1870); de él se decía ser «la maravilla de los gimnásticos del mundo entero» (Diario de Barcelona, 23 de octubre 1860, p. 2), el "Rey de la gimnástica» (Diario de Barcelona, 14 de octubre de 1860, p. 2). Luego viajó por España y fue muy aplaudido en Madrid donde actuó en los circos de Paul y Price. Milá fue reconocido uno de los mejores gimnastas del mundo en el trapecio (Dalmau, 1947). Ya de mayor, se dedicó a la aeronáutica y dispuso de su propia compañía de circo en la que actuaron como trapecistas los hermanos Andreu, uno de ellos, Pedro Andreu, fue el padre del famoso clown Charli Rivel -Josep Andreu i Lasserre- (1896-1983).

En 1860 volvemos a encontrar publicidad del Gimnasio para ambos sexos de los hermanos Luis y Francisca Vall, en la c/ de Guardia, 15 cuarto bajo, que en 1862 se anunciaba como Gimnasio Higiénico Catalán, dirigido por los profesores Luis, José y Manuel Vall. Se decía que este era el más antiguo de la ciudad, con una experiencia de catorce años (Hermanos Vall, 1862). Encarecían la gimnasia especialmente para paliar el sedentarismo de las mujeres, para el desarrollo muscular del

\footnotetext{
${ }^{8}$ Puede aparecer también como José Florencio Cuadras.
} 
pecho y contra la tisis pulmonar. Los hermanos Vall trataban de advertir a los padres que la gimnástica que ellos aplicaban nada tenía que ver con la que se exhibía y se propagaba desde las populares compañías gimnásticas; su método de enseñanza era higiénico y pedagógico:

Haciendo la debida diferencia entre la gimnástica higiénica y la escénica, podrán los señores padres deponer sus temores, y proporcionar a sus hijos las ventajas que las ofrecemos por medio de su desarrollo progresivo.

Inútil nos parece prometer todo cuidado y vigilancia, ya que acreditado lo tenemos en el tiempo que llevamos de enseñanza en diferentes establecimientos, entre otros el de los Padres escolapios y el de señoras de Loreto. (Vall y Vall, 1860, p. 26).

Hay que destacar que, en 1862, Francisca Vall, después de visitar, según decía, los mejores gimnasios en el extranjero, instaló por cuenta propia un gimnasio de uso «exclusivo para señoras» en la c/ de la Palma de San Justo, 14 que se anunciaba como "Gimnasio higiénico de Barcelona» (Vall, 1862, p. 10062). Más tarde, este gimnasio se trasladó a la c/ Obradors, 8 y se anunciaba con el nombre de «Gimnasio Barcelonés, Médico higiénico y ortopédico, exclusivo para señoras», bajo la dirección de José y Francisca Vall "y por un inteligente y reputado facultativo"; se añadía recibir "a todas horas, también hay consultas para enfermos y defectuosas» (Vall y Vall, 1867, p. 7629).

Florencio Quadras (1861, p. 10102) era el director de la Sociedad Círculo Gimnástico Barcelonés, en Plaza Real, 1 -en el subterráneo del barón de Châtre-, pero se trasladó a otro local más amplio, ventilado y más ventajoso «para los beneficios que a la parte higiénica proporcionan los ejercicios gimnásticos». Este se ubicó en la c/ Nueva de San Francisco, 11 y 13 [Figura 11]. Quadras se dirigía a las señoras y niñas, puesto que garantizaba la «independencia completa del local destinado para las personas del otro sexo», pero también a todas aquellas personas de vida sedentaria con objeto de aumentar las «fuerzas corporales del individuo para la conservación de la salud» (Barcelona, 1861, p. 10102).

La afición a los ejercicios gimnásticos toma cada día mayor incremento en Barcelona, a medida que se tocan sus buenos resultados para el desarrollo de la juventud, y que se ven palpablemente en personas que, absorbidas por los negocios o por los estudios tenían antes de practicar aquellos ejercicios una salud delicada, y ahora gracias a ellos han logrado fortalecerla y aun adquirir una notable robustez. (Quadras, 1862, p. 8980). 


\section{Parde ecenzonatea. \\ CÍRCULO GIMRÁSTICO BARCELOWÉS,}

CALLE NUEVA DE SAN FRANCISCO, NUM. 11 Y 13.

Director de Ia Gociedad, D. José Florencio Quartras.

Se avisa d̂ los señores que da el concurren, que las lecciones han empezado el $1 .^{\circ}$ de octubre por $\mathrm{s}$ desean renovar los ejercicios gimnasticos, ó bien acompañar las personas do su agrado.

El gimnasio podrán visitarlo las personas que gusten durante las horas de ejercicio, a escepcion de las destinadas a las señoras y enfermos, que seran reservadas.

(Señoras, $7 \mathrm{rs}$. al mes, y 180 por trimestre.

precios Caballeros $10 \mathrm{rs}$, al mes, 105 trimestre, 200 semestre, y 360 al año.

(Bnfurmos y defectuosos, precios convencionales.

De $711^{2}$ a 9 de la mañana para caballeros.

De 9 a 10 id. para las señoritas.

De 10112 á 12 id. para enfermos y defectuosos.

Horas de ejercicio. $\left\{\begin{array}{l}\text { De } 12 \text { a } 1 \text { 1 } 12 \text { para enfermas y defectuosas. } \\ \text { Do } 111^{2} \text { a } 3 \text { para caballeros. }\end{array}\right.$

De 1 a 5 para ninas.

De 7 a 8 de la noche para nitios.

De 8 i 9112 para cabúlleros.

Las comúnicaciones del cuarto y entrada de las señoras y caballoros están independientes.

En cuanto $a$ las buenas condiciones de mucha capacidad, luz, altura y ventilacion que reane el establecimiento, ereo inútil esplicarlo, pues que los señores concurrentes se persuadirán por sí mismos, como tanbien de la saiubridad del local que carecia el antiguo situado en los sótanos de la plaza
Real, por cuales motivos tan necesarios se traslado al actual.

Figura 11. Diario de Barcelona, 9 de octubre de 1862. Fuente: ARCA.

Quadras fue un destacado alumno del Colegio Barcelonés y se formó en la gimnástica de la mano de Carlos Berthier y de Bernabé Barrio (Colegio Barcelonés, 1848) y, más tarde, fue profesor de gimnasia del prestigioso Colegio Carreras (TorrebadellaFlix, 2015). Quadras tenía de socio a Mr. Vignolles el cual se fue a Madrid en donde se estableció por cuenta propia (Torrebadella-Flix, Rivero-Herraiz y Sánchez-García, 2019).

Un destacado colaborador de Quadras fue Joaquín Ramis Taix (1831-1910) [Figura 12], que erróneamente se le atribuye que dispuso del primer gimnasio higiénico de la ciudad en 1860 (Balius, 1985; Masriera, 1924):

El entusiasmo e interés despertado por estos espectáculos [gimnásticos] dejaron el terreno abonado para que un verdadero apóstol de la gimnasia, don Joaquín Ramis, estableciera en Barcelona el primer gimnasio higiénico recreativo. [...] Su sistema curativo se hizo famoso y aun hoy viven algunos de los enfermos que, desahuciados de los médicos, puestos en manos de Ramis, lograron salir indemnes de su enfermedad. (Masriera, 1924, pp. 37-41).

Ramis, que había nacido en Barcelona en 1831, se inició en la gimnástica a la edad de dieciséis años, allá por el año de 1847, de la mano de los mejores profesores de la ciudad:

Cumple a mi deber pagar en este momento un tributo de gratitud y aprecio a mis queridos Profesores, a quienes debo los pocos adelantos que llevo hechos en la Gimnástica tales son: los Sres. D. Francisco Barrios, D. Pedro Verthier y D. Manuel Valls; nombres que recordaré siempre con veneración y respeto, con amor y cariño fraternal. (Ramis, 1865, pp. 3-4). 
Además, Ramis estuvo asociado al profesor Quadras hasta llegar a 1858, en el que ambos se independizaron (Torrebadella y Arrechea, 2015). Poco después, el Círculo Gimnástico Barcelonés de la Plaza Real, 1 pasó a denominarse "Gimnasio Español», ya en propiedad y dirección de Ramis (Balius, 1985; Ramis, 1865). Allí cobraba por las clases 25 reales al mes a los caballeros y 50 a las señoras (Gimnasio Español, 1863, p. 4). En los primeros años, Ramis contó con la colaboración de Pedro García Corbera (1833-1903) quien, hacia 1868, se establecería por cuenta propia en un nuevo gimnasio de la villa de Grácia (Torrebadella y Arrechea, 2015).

En 1865, Ramis se ofreció como profesor de gimnástica al director de la Escuela Normal de Barcelona, Odó Fonoll. Esta oferta fue aceptada por la Diputación de Barcelona con la condición de que las clases fueran libres y gratuitas. Así que, con estas condiciones, Ramis impartió las clases de gimnástica en las dependencias de su propio gimnasio, hasta 1877 (Monés, 2000).

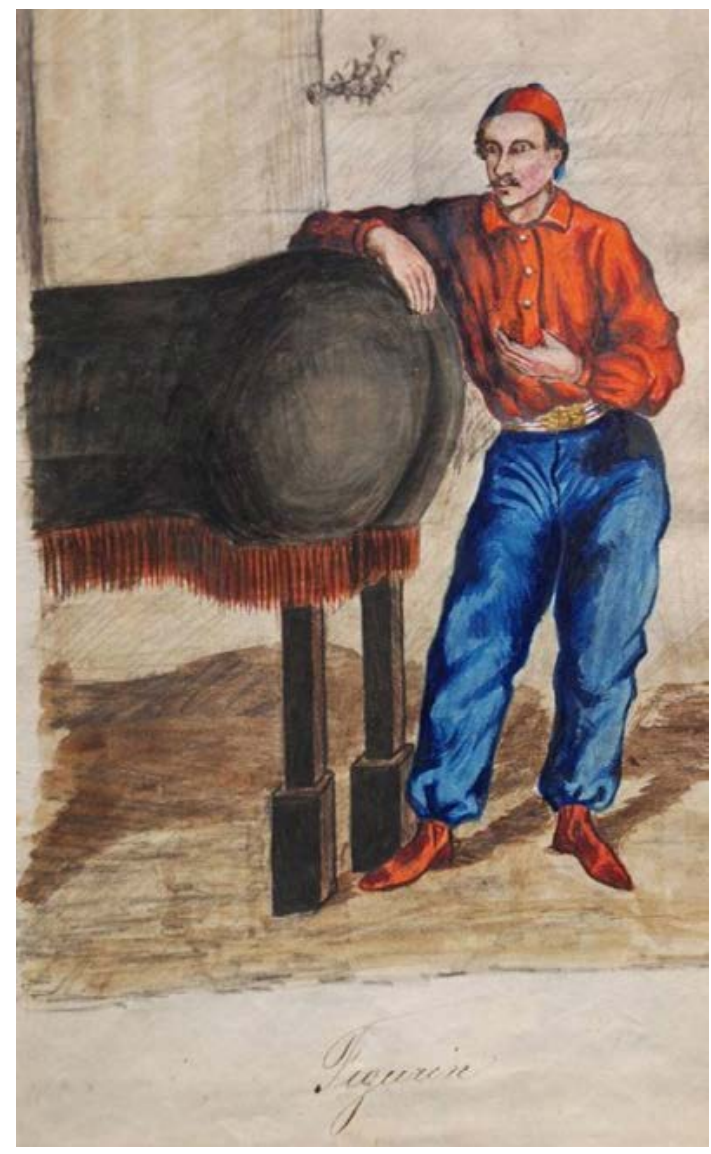

Figura 12. El gimnasiarca Joaquín Ramis. El Trapecio (Semanario Guasón redactado por una compañía de titiriteros del Círculo Gimnástico Barcelonés) 1860. Fuente: http://librorum.piscolabis.cat/2009_01_01_archive.html. 
Podemos citar que el gimnasio de Ramis inauguró un nuevo período, el de la gimnasia higiénica, el cual venía auspiciado por la aparición del Manual popular de gimnasia de sala, médica e higiénica del Dr. Schreber (1861) «o representación y descripción de los movimientos gimnásticos que, no exigiendo ningún aparato para su ejecución, puede practicarse en todas partes y por toda clase de personas de uno y otro sexo; seguido de sus aplicaciones a diversas enfermedades» (Libros, 1861, p. 7082; Torrebadella, 2014b).

A finales de los años sesenta se establecieron otros gimnasios, como el citado de Pedro García en el barrio de Gracia en la c/ Mayor, 113 o el de Fidel Bricall Segura, en la c/ Cortinas, 8, también profesor de gimnasia del cuerpo de Bomberos (Llaverias, 1906; Torrebadella y Arrechea, 2015).

Por lo tanto, ya podemos dar crédito a la afirmación del doctor Tomas Casals (1860, p. 2), profesor de gimnástica del Instituto de Lérida, cuando aludía que en Barcelona se habían establecido numerosas escuelas de gimnástica «a contar desde el conocido gimnasiarca Berthier hasta el reputado profesor Valls, son infinitos los maestros que las ha establecido en los últimos doce años» (Torrebadella, 2012b). Pero, además, como identifican Torrebadella y Arrechea (2015), la gimnástica entró a formar parte de ateneos, asociaciones y otras entidades privadas. En el Círculo de Dependientes de Comercio de Barcelona (1863) en el curso 1863/64 aparecían unas clases de gimnástica impartidas por los hermanos Vall -martes, jueves y sábados de ocho a nueve de la noche-. Por su parte, el citado profesor Quadras, que también fue profesor de este Círculo, en 1864, abría una cátedra de gimnasia en el Ateneo Catalán de la Clase Obrera. Ambas entidades fueron creadas en 1861 (Torrebadella y Arrechea, 2015).

En 1859 la nueva organización del Círculo Ecuestre de Barcelona - con unos 150 socios- se estableció en nuevo local en la Rambla de Santa Mónica, integrando en él dependencias para practicar el sport, tal y como se estaba haciendo en otras ciudades del extranjero. El nuevo local dispuso de gimnasio, sala de armas, tiro de pistola, billares...

Hoy día que el Sport es el complemento de toda educación, se hacía sentir en Barcelona la falta de un establecimiento que, reuniendo todo lo útil a lo agradable, sirviera de centro de reunión a la juventud que desea adiestrar en todos los ejercicios del cuerpo propios a desarrollar las fuerzas las fuerzas físicas. Si bien es verdad que había a en esta Ciudad varios establecimientos de esa clase, también lo es que no hay ninguno que reúna por si solo todos los elementos dispersos y que son de desear reunidos para la mayor comodidad de los aficionados. (Costa, 1859, p. 7453).

Además, hay que destacar que todo un referente a la recreación y el espectáculo como era el Teatro del Liceo de Barcelona consiguió las actuaciones de los 
mejores acróbatas de la época, Blondin en 1863 o el estadounidense Haslam -el más directo rival de Leotard en el trapecio. No obstante, crítica Dalmau (1947) que el Liceo tardó algunos años en exhibir los ejercicios de Leotard.

En 1860 este extraordinario gimnasta estaba acaparando los aplausos del Circo del Hipódromo de París. De él se decían muchos elogios y de las rivalidades que mantenía con otros trapecistas, pero también se aprovechaba para destacar las ventajas de la gimnástica para reducir los efectos de la degeneración:

Leotard es el héroe del verano porque ha introducido un nuevo género de trabajo -nos valemos de la expresión sancionada por los señores equilibristas y gimnásticos-; Leotard, o el hombre trapecio, se lanza de un extremo a otro del Circo cogiendo al vuelo trapecios escalonados de trecho en trecho. A pesar de lo que se diga en contra, conservamos aun el culto a la fuerza, y a la agilidad del cuerpo, y nada lo prueba más que los aplausos y el entusiasmo que arranca Leotard.

¿Incurrimos en un grave error no constituyendo con la gimnástica la base de la educación social? Cuestión es esta susceptible de discutirse, pero forzoso es confesar que los hombres robustos son los que retardan la degeneración de la raza humana. (H., 1860, p. 5620).

Pero el que fuera considerado el mejor trapecista del mundo no llegaría a Barcelona contratado por el Liceo hasta el 8 de enero de 1868 donde permanecería un mes representando con gran éxito las «Maravillas gimnásticas» (Espectáculos públicos, 1868, p. 2). Aparte de ofrecer este espectáculo, Leotard impartió lecciones en varios gimnasios de la ciudad. Así conoció el gimnasio del profesor Juan Estrany $y$, también, el de los hermanos Vall donde le fue otorgado el título de profesor honorario (Crónica local, 1868).

Así también debemos dar crédito a las palabras de Joaquín Lladó (1868, p. 11), usuario del gimnasio de los hermanos Vall, durante catorce años, cuando mencionaba que en pocos años el gimnasio había experimentado un «incremento extraordinario», "a los cuales asisten diariamente gran número de alumnos de ambos sexos» [Cuadro 1].

Para concluir este primitivo período en la configuración del gimnasio moderno, solo falta por destacar el libro de Nociones de gimnástica higiénica de Lladó (1868) [Figura 13], que según se ha dicho: «fue el primer gran tratado pedagógico de educación física que se publicó en España incorporando, además, un capítulo a la gimnástica del sexo femenino» (Torrebadella y Olivera, 2012, p. 144).

Lladó (1868, p. 13) mencionaba que, si bien para algunos la gimnástica era vista como una moda, la mayoría iba al gimnasio para buscar el «vigor y la salud»; es decir, compensar el sedentarismo y las costumbres que imponía la vida en las grandes ciudades. De aquí que la gimnástica se tuviese como un medio regenerador, preventivo y curativo de algunas enfermedades. No obstante, en el tratado de 
Lladó se percibe un provocativo espíritu crítico al destacar al poco interés que esta materia despertaba en España:

He aquí, pues, cuanto se equivocan los que atribuyen a la moda la afición a la gimnástica: afición que sería mucho mayor si a semejanza de otros países se le diese en España más importancia, y si sus resultados fuesen debidamente conocidos y apreciados por todos.

Las más adelantadas naciones miran con mucho interés el estudio de la gimnástica. En Sajonia es obligatoria su enseñanza, y a fin de que los maestros puedan ponerla en práctica en las escuelas existe un Gimnasio normal en Dresde donde la aprenden. (Lladó, 1868, p. 25).

Joaquín Lladó también criticó las condiciones de los locales, pero, sobre todo, la inopia del Gobierno incapaz de percatarse de los provechosos beneficios de la gimnástica, no solamente físicos, sino también morales y sociales.

El gobierno podría más fácilmente llevarlos a cabo. Siendo la gimnástica tan útil para el desarrollo físico sería de desear que estableciera grandes gimnasios, siquiera en las capitales de provincias, arreglados conforme todas las reglas de la higiene y de la ortopedia y en las cuales además de los directores hubiese un facultativo que sirviese de guía en ciertos casos que solo a ellos toca resolver.

Pero mientras no existan gimnasios en edificios construidos apropósito preciso será que nos resignemos contentándonos con que los haya aunque no reúnan todas las condiciones apetecibles. Deber es, sin embargo, de los directores de tales establecimientos sacar todo el provecho posible de los locales de que se ven precisados a echar mano, y buscar siquiera los que reúnan mejores condiciones higiénicas. (Lladó, 1868, p. 92).

De todos modos, las palabras de Lladó, que no eran infructuosas, no tendieron los estímulos suficientes para que las instancias políticas se percataran del poder de la gimnástica, ni siquiera en el orden militar se apreciaba su provechosa aplicación. Sobre esta cuestión, Lladó (1868, p. 123) mencionaba "no es extraño que España no haya imitado en esto a otras naciones adelantadas». Por último, Lladó terminaba la obra haciendo un llamamiento a todas aquellas personas que a bien pudieran influenciar al Gobierno sobre la utilidad de la gimnástica y la educación física. 


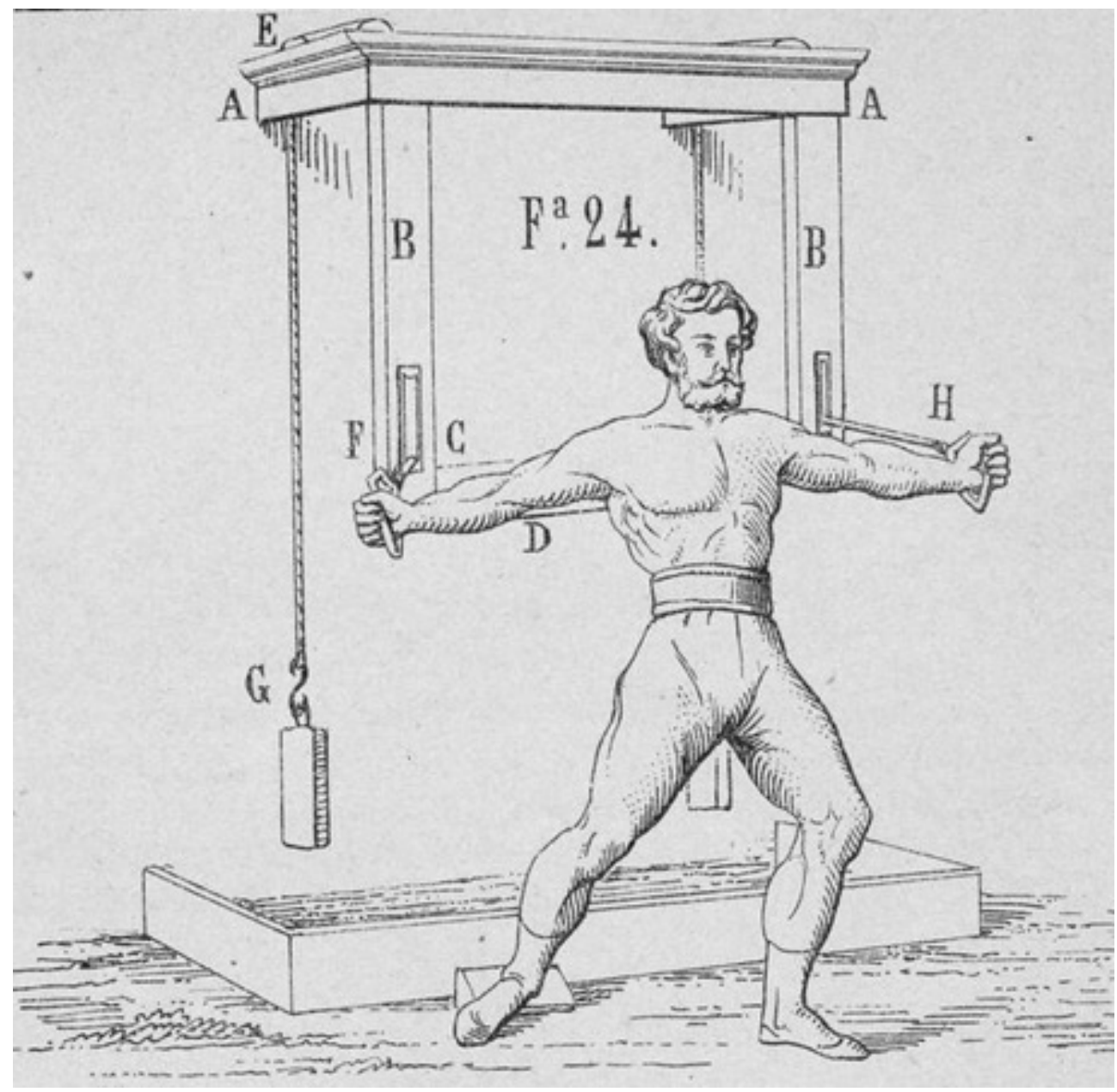

Figura 13. Lámina 11. Joaquín Lladó (1868). Nociones de gimnástica higiénica. Fuente: autor. 
Cuadro 1. Gimnasios instalados en Barcelona entre 1837 y 1868 (Exploración provisional)

Año

Denominación y dirección

Ubicación

1837 Gimnasio Ortopédico de Pedro Font.

c/ Lladó, 12.

1837 Gimnástica en el Instituto Barcelonés. En 1847 Gimnasio

c/ Bonsucces, Colegio Barcelonés. exconvento Elisabets.

1842 Centro ortopédico y gimnástico de Pablo Clausolles.

c/ del Pino, 2.

1844 Instituto Gimnástico Barcelonés.

Desconocida.

1845 Escuela de gimnástica militar dirigida por D. N. Barrios (Diario de Barcelona, 1 de marzo de 1845).

Atarazanas (En El patio de ingenieros de San Agustín Viejo).

1848 Escuela de Gimnástica de Mr. Berthier. Cursos de gimnástica y natación.

1848 Gimnasio del Colegio Barcelonés bajo la dirección de Bernabé Barrio.

1848 Gimnasio hermanos Vall (Vall y Vall, 1862).

c/ de Cirés, 5.

1850 Escuela de gimnástica de Manuel Vall. Según Dalmau (1947) ya existía en 1845 .

1851 Gimnasio del Regimiento de Astorga, dirigido por Juan Moreno y Manso.

c/ Elisabets.

Puente de la Parra.

Puente de la Parra.

Casino Militar (antiguo Convento de la Mercé).

1851 Gimnasio Civil y Militar de Mr. Dasseville (Mr. Berthier).

c/ de Cirés, 5.

1853 Sala de armas de Eudaldo Thomase: «La esgrima es el principal ejercicio de la gimnástica».

Puerta de Santa

Madrona, 20.

1853 Gimnástica Ortopédica para señoritas de María de la Asunción Berthier..

c/ Del Mediodía, 9.

1854 Enseñanza de Gimnasia bajo la dirección de José Vall.

c/ Avellana, 5.

1857 Gimnasio particular de Juan Estrany.

Plaza Beato Oriol, 4.

1857 Eudaldo Thomase: «Gimnástica higiénica».

Puerta de Santa

Madrona, 20.

1857 Academia de Gimnástica de Juan Vall. En 1871 era el «Gran

c/ de Rull, 2 (frente a Gimnasio Europeo» de Luis Vall. la c/ Obradors). 
1858 Colegio de los señores Figueras y Arquer. Clase de gimnástica

c/ Lladó, 4.

higiénica en el mismo gimnasio del colegio a cargo del aventajado profesor Manuel Vall (Diario de Barcelona, 12 de septiembre de 1858).

1858 Gimnasio de Joaquín Ramis, Florencio Quadras y Mr. Vignolles (Ramis, 1865, p. 7).

1859 Gimnasio higiénico-recreativo de Antonio Moratones.

c/ Gobernador, 2.

1859 Gimnasio del Círculo Ecuestre.

Rambla de Santa

Mónica

1860 Gimnasio Ortopédico Normal Barcelonés de Carlos Berthier.

c/ Ramalleras, 16.

1860 Círculo Gimnástico Barcelonés, dirigido por José Florencio. Quadras. Continuó como Gimnasio Español de Joaquín Ramis.

1860 Gimnasio para ambos sexos de Luis y Francisca Vall, hermanos (Diario de Barcelona, 2 de enero). En 1862 llamado Gimnasio Higiénico Catalán.

Plaza Real, 1.

c/ de Guardia, 15 (cuarto bajo).

1861 Círculo Gimnástico Barcelonés, dirigido por José Florencio Quadras.

Calle Nueva de San Francisco, 11 y 13.

1861 Gimnasio Español de Joaquín Ramis (Diario de Barcelona, 26 Plaza Real, 1. de noviembre).

1862 Gimnasio higiénico y curativo de Antonio Moratones (Diario de Barcelona, 28 de septiembre).

1862 Gimnasio higiénico de Barcelona, exclusivo para señoritas por Francisca Vall (Diario de Barcelona, 11 de noviembre de 1862).

1865 Gimnasio Modelo de Manuel Vall y Cardona (La Corona, 3 de marzo de 1865).

1865 «La Regeneración del hombre»: Gran Gimnasio Europeo, Higiénico y Ortopédico, directores José y Luis Vall y María Vall c/ de Magdalenas, 3. c/ Palma San Justo, 14.

c/ Mendizabal, 17.

c/ de Rull, 2. (Lloyd Español, 19 de noviembre de 1865).

1867 Gimnasio Barcelonés «Médico higiénico y ortopédico, exclusivo para señoras», dirigido por José y Francisca Vall.

c/ Obradors, 8. Gimnasio Higiénico de Fidel Bricall. c/ Cortinas, 8, 1.․ 


\section{CONCLUSIONES}

Durante el Período Liberal Barcelona estuvo sumida en un ambiente político hostil. Los capitanes generales tuvieron a la ciudad en un permanente estado de sitio. Aun así, se manifestaba una incipiente actividad empresarial, coligada a intereses particularidades y totalmente desvincula de la política o de expresiones nacionalistas.

Como indica Fontana (2015), el Estado Liberal- intrincado en la ceguera de las mentalidades provincianas- rechazó absolutamente la industrialización o modernización del país, las oligarquías castellanas tenían miedo a la libertad de las ideas, a la revolución socialista o comunista. Con lo cual, los políticos liberales no estuvieron a la altura de los cambios que se estaban produciendo en Francia, Inglaterra o Prusia, países en los que también la coyuntura liberal se forjaba de discursos renovadores, progresistas y nacionalistas. En estos países, el gimnasio, la gimnástica escolar y las asociaciones gimnástico-deportivas entraban en esa configuración metafórica que en volvió a la modernidad de las naciones, a saber, la regeneración del hombre y la idealización de un hombre nuevo. Pero en España no se alimentaron argumentaciones de progreso y de concienciación colectiva eficaces. El débil espíritu nacionalizador quedó relegado a un sistema educativo insuficiente, libresco y de escaso reconocimiento científico y humanístico, eso sí, se delató la inopia de considerar la nación sobre un patriotismo forzado de mitologías históricas (Álvarez Junco, 2001).

La revolución burguesa en España fracasó por partida doble. Por un lado, no supo seguir el tren de la revolución industrial y, por el otro, el liberalismo no articuló un discurso de comunión popular. Puede decirse que todo ello venía supeditado a la incapacidad de ofrecer una respuesta a las aspiraciones liberales catalanas. Por lo tanto, en esta coyuntura la gimnástica quedó al margen de cualquier vía nacionalizadora. Este no fue el caso, por ejemplo, de Alemania (Mosse, 2005) y, posteriormente, el de Francia y el de otros países de Europa que supieron utilizar en la edificación nacional el poder de la educación gimnástica y de un asociacionismo gimnástico-patriótico.

Los gimnasios de Barcelona evidenciaban el apogeo de la gimnástica de Amorós y algunos de sus discípulos fueron los que dieron a conocer la gimnástica entre la ciudadanía. Sin embargo, esta gimnástica estaba desligada de predicados patrióticos y, por otro lado, la represión militar no ayudaba para nada que emergiera un discurso edificador de un nacionalismo español constitucionalista, como así sucedió en el Trienio Liberal con la institucionalización popular de un movimiento gimnástico-militar. También hay que considerar que, si bien existió una desconexión de la política catalana con la del Estado, se mantuvieron unas resistencias sociales prerevolucionarias que desencadenaron represivas intervenciones -supresión de las garantías constitucionales y un estado de excepción permanente- que afectaba al 
poder municipal, con lo cual, la emergencia de un asociacionismo gimnástico de signo patriótico quedaba completamente imposibilitada.

De todos modos, la singularidad española marcó, con diferencia, los sucesos que acontecían en Europa, y ningún otro país desfiló por una situación tan convulsa. Con lo cual, solamente una ciudad como Barcelona - «la fábrica de España»-, que lideraba en Cataluña un proceso de modernización sobre una nacionalidad muy distinta a la española (o castellana), podía servir de modelo para sacar al país del aprieto. Efectivamente, la debilidad de la nación española estaba sumamente cuestionada al no seducir a las capas populares de las diferentes nacionalidades existentes en el país. Sobre este aspecto se puede inducir que existió un patriotismo español circunstancial, pero este nada tenía que ver con los militares, la iglesia y la aristocracia política y dirigente.

Sobre el doble patriotismo tratado por Fradera (2003), pensamos que no era sino una evasiva protectora de los intereses personales de ciertas elites y cuyo progreso estaba ligado a los compromisos clientelares con el Estado castellano. Esta ambigüedad pudo ser un elemento que frenó los anhelos de utilizar un elemento gimnástico de matriz militar o popular, como la creación de asociaciones gimnásticas de perfil patriótico, lo cual hubiera representado una posición beligerante por parte del catalanismo. Por otro lado, el Estado no podía proyectar políticas nacionalizadoras de este tipo sin la pacificación y sumisión catalana, que era el principal núcleo del país en el que podía arrancar un asociacionismo gimnástico patriótico.

Que la gimnástica estuviese desvinculada de un ideario de identificación nacional o patriótico, se visibilizó en la usencia de esta enseñanza en la escuela pública, pero las escuelas privadas, que sí la contemplaron, solamente fue por su carácter inminentemente higiénico y moralizador, es decir, coligado a una respuesta fundada con el seny de Balmes.

Por consiguiente, la gimnástica y el gimnasio en Barcelona surgió en la confluencia y la configuración de un paradigma urbano y económico, desvinculado de cualquier matiz nacionalista o patriótico. Nadie en Barcelona pedía que el Estado proyectase un Gimnasio Normal como así lo expresaba el Conde de Villalobos en Madrid; eso sí, se pedía el cese de la represión sobre la ciudad y el pueblo catalán, se pedía mayor progreso industrial, pero también más democracia y justicia social.

Con lo cual la gimnástica, desestimada de su aspecto militar y patriótico, pero amparada por el marco ideológico del liberalismo catalán, conformó un aspecto público más enraizado en la cultura urbana y vinculado a una mirada higiénico-médica, educativa o recreativa y cuyo objetivo se centraba en la vida saludable, lo cual se presentó como signo de distinción de clase entre los elementos de la burguesía liberal. Sobre esta realidad social, el gimnasio moderno se integraba en un proceso de civilización acompañando el auge industrial y comercial de una ciudad que aspiraba a su renovación. En este sentido se manifestaba el seny de Balmes (1845). 
La idea de la degeneración de la especie humana residía en la creencia que las generaciones actuales, nacidas en la atmosfera de las grandes ciudades, heredaban las debilidades, los vicios y las enfermedades de las anteriores generaciones, por eso había que refugiarse en el campo para renovar los regímenes de vida y vigorizar los cuerpos. Y, sobre este paradigma, se reconocía que las experiencias gimnásticas y los gimnasios higiénicos podían frenar esta degeneración y reparar o regenerar los cuerpos medio destruidos.

Aparte, el auge cultural de la Renaixença no acercó el culto al cuerpo y eso amortiguó las susceptibilidades hacia un discurso de exaltación étnica. Si bien encontramos manifestaciones que señalan las carreras a pie -o cossos- y ciertos juegos corporales, estos estuvieron despojados de connotaciones nacionales o patrióticas (Planas y Torrebadella, 2017).

Finalmente, podemos afirmar que a partir de la propaganda y del conocimiento de los primeros gimnasios de Barcelona se extendió y se propagó hacia todo el país las primeras iniciativas de la gimnástica higiénica, educativa y moderna. Este fue el punto de inicio hacia la cultura físico-deportiva de una ciudad que durante décadas persiguió el sueño de organizar unos Juegos Olímpicos, como así lo idealizó Aribau (1820), hace ya doscientos años (Torrebadella y Arrechea, 2015).

\section{REFERENCIAS}

Academia de Medicina Militar de Barcelona (1851). La Abeja médica-Barcelona-, 5(7), pp. 230-241.

Álvarez Junco, J. (2001). Mater dolorosa. La idea de España en el siglo XIX. Madrid: Taurus.

Amorós, F. (1850, 23 de septiembre). Bandas metálicas para billar. El Barcelonés, p. 4.

Amorós, F. (1856, 24 de mayo). Carpintería en General Don Francisco Amorós. Diario de Barcelona, p. 9.

Amorós, F. (1866). Manual para los aficionados al juego de billar. Barcelona: Imp. de Gómez e Inglada.

Amorós, F. (1868). Resumen histórico de las exposiciones: y memoria descriptiva de la fabricación de la mesa de billar presentada a la Exposición de París de 1867. Barcelona: Est. Tip. de Narciso Ramírez. 
Andrieu, G. (1992). Force et beauté. Histoire de l'esthétique en Education Physique aux XIXe et XXe siècles. Bordeaux: Presses Universitaires de Bourdeaux.

Anoche asistimos... (1851, 18 de marzo). El Áncora-Barcelona-, pp. 1-2.

Arañó, M. (1852). Higiene moral y física: o sea, salud del alma, y salud del cuerpo. Barcelona: Imp. de J. Tauló.

Aribau, B. C. (1820, 24, 25 de julio). De la gimnástica y de las artes mecánicas consideradas como parte de la educación. Diario Constitucional, político y mercantil de Barcelona, pp. 2-3 y pp. 1-3.

Arnabat, R. A. (2004). La revolució liberal a Barcelona. Política de classes i classes de política. Barcelona Quaderns d'història, 10, pp. 11-58.

Arnús, M. (1853). La Puda: establecimiento de aguas minerales sulfurosas... Barcelona: Joaquín Verdaguer.

Ateneo de la Clase Obrera (1864, 16 de agosto). Lloyd Español-Barcelona-, p. 2.

Balius, R. (1985). El gimnas i la gimnàstica higiénica del señor Ramis. Apunts de Medicina de l'Esport, 85, pp. 109-112.

Balmes, J. ([1845]1851). El Criterio (3.a ed.). Barcelona: A. Brusi.

Balmes, J. (1843). La Sociedad. Revista religiosa, filosófica, política y literaria. Barcelona: Imp. del Diario de Barcelona.

Balmes, J. (1847). Escritos políticos. Barcelona: Imp. de la Sociedad de operarios del mismo Arte.

Barbero-González, J. I. (2012). El darwinismo social como clave constitutiva del campo de la actividad física educativa, recreativa y deportiva. Revista de Educación, 359, pp. 580-603.

Barcelona (1844, 6 de diciembre). Barcelona. Diario de Barcelona, pp. 4954-4955.

Barcelona (1845, 1 de marzo). Barcelona. Diario de Barcelona, pp. 822-823.

Barcelona (1850, 24 de diciembre). Barcelona. Diario de Barcelona, p. 6850. 
Barcelona (1855, 4 de noviembre). Don Manuel Vall y Cardona. Diario de Barcelona, p. 4.

Barcelona (1858, 8 de junio). Mr. Vigorolle profesor, de boxe... Diario de Barcelona, pp. 5156-5157.

Barcelona (1862, 6 de enero). Los ejercicios gimnásticos... Diario de Barcelona, pp. 162-163.

Bastús y Carrera, V. J. (1833). Diccionario histórico enciclopédico. Tomo III. Barcelona: V. de D. A. Roca.

Benet, J., y Martí, X. (1976). Barcelona a mitjan segle XIX. EI Moviment obrer durant el Bienni Progressista (1854-1856). Barcelona: Curial.

Berthier, C. (1860, 20 de marzo). Gimnasio Ortopédico Normal Barcelonés. Diario de Barcelona, p. 2699.

Berthier, M. (1853, 13 de diciembre). Aviso a los padres de familia. Diario de Barcelona, p. 9019.

Bertier (1848a, 21 de enero). Escuela de gimnástica. Diario de Barcelona, p. 334.

Bertier (1848b, 23 de diciembre). El señor Bertier profesor... Diario de Barcelona, p. 5979.

Bertier (1854, 25 de noviembre). Teatro Circo Barcelonés. Diario de Barcelona, p. 8317.

Bertier, C. (1858, 22 de mayo). Habiendo Regresado a esta capital. Diario de Barcelona, p. 4654.

Boix, V. (1846, 1 y 15 de marzo). Apuntes para la bibliografía del Coronel D. Francisco Amorós, marqués de Sotelo. El Fénix -Valencia-, pp. 262-263; pp. 281-282.

Bosch, J. (1851). Discurso pronunciado en la Academia Médico-Castrense de Barcelona, sesión del 4 de abril de 1851 ... sobre el punto siguiente: ¿Qué medios pudieran adoptarse para mejorar la constitución física y moral del recluta, y acostumbrarlo a la vida militar?, Biblioteca Médico-Castrense Española, 8, pp. 339-352. 
Busqué, S. (1865). Gimnástica higiénica, médica y ortopédica o el ejercicio considerado como medio terapéutico. Madrid: Imp. Manuel Galiano.

Campos Eliseos (1854, 26 de octubre). Diario de Barcelona, p. 1.

Casals, T. (1860, 25 de septiembre). Estudios fisiológicos. La gimnástica en España. El Alba Leridana, pp. 1-2.

Català, J. (1821). Manual práctico o compendio del método de enseñanza mutua que ha reglamentado y da a la luz para las escuelas de Cataluña y demás de España. Barcelona: Imp. José Torner.

Chapus, E. (1854). Le Sport a Paris. Paris: L. Achette et Ca.

Círculo de Dependientes de Comercio de Barcelona (1863, 28 de octubre). Círculo de Dependientes de Comercio de Barcelona. La Corona, p. 8.

Coca, A. (1862). Tratado de terapéutica general. Barcelona: Imp. Diario de Barcelona.

Colegio Barcelonés (1848, 3 de noviembre). Anteayer a las doce de la mañana... Diario de Barcelona, pp. 5132-5133.

Commentant, O. (1862, 10 de noviembre). El espíritu y el cuerpo. Diario de Barcelona, pp. 10042-10043.

Cortada, J. (1860). Cataluña y los catalanes (2.a ed.) S. Gervasio: Imp. de Miguel Blanxart.

Costa, M. (1859, 17 de julio) Barcelona. Diario de Barcelona, pp. 7453-7455.

Cots, F. (1851, 23 de marzo). Anuncios oficiales. Diario de Barcelona, p. 12.

Crónica local (1868, 27 de enero). El Principado, -Barcelona-p. 596.

Cubí, M. (1852). Al pueblo español sobre las causas que hacen el comunismo imposible i el progreso inevitable. Barcelona: Jaime Gaspar.

Cucurull. F. (1975). Panoràmica del nacionalisme català: Del 1814 al 1874. Paris: Edicions catalanes de Paris. 
Dally, N. (1848). Gymnastique. De la régénération physique de l'espèce humaine par la gymnastique rationelle. Paris: Imp. Paul Dupont.

Dalmau, A. R. (1947). El circo en la vida barcelonesa. Crónica anecdótica de cien años circenses. Barcelona: Ediciones Librería Milla.

Dassevelle, C. (1848, 21 de agosto). Cursos de Gimnástica y Natación. Diario de Barcelona, p. 3913.

Dassevill, C. (1848, 6 de agosto). Ha llegado a mi noticia. Diario de Barcelona, pp. 3659-3660.

Dasseville (1851, 13 de enero). Gimnasio Civil y Militar. El Sol-Barcelona-, p. 3.

De Fabregues, S. N. de (1868, 14 de noviembre). Educación de la mujer. Moda Elegante llustrada, pp. 336-338.

De Lasalle, X. (1861, 1 de agosto). Fiesta Gimnástica en Gubwiller. El Correo de Ultramar, n.․ 448, p. 4.

De Riquer, B. (2001). Escolta, Espanya. La cuestión catalana en la época liberal. Madrid: Marcial Pons.

De Villalobos, C. (1842). Ojeada sobre la jimnasia, utilidades y ventajas que emanan de esta ciencia. Madrid: Imp. de Yenes.

Debreyne, J. C. (1862). Compendio de fisiología humana para servir de introducción a los estudios de filosofía y de la teología moral. Barcelona:

Del Castillo, J. (1837). Las Bullangas de Barcelona, o Sacudimientos de un pueblo oprimido por el despotismo ilustrado. Barcelona: Imp. De A. Gaspar y Compañía.

Diario de Barcelona (1844a, 1 de mayo). Parte económica. Avisos. Diario de Barcelona, p. 1819.

Diario de Barcelona (1844b, 6 de diciembre). Barcelona. De los diarios de Ayer. Diario de Barcelona, pp. 4954-4055.

Durán y Bas, M. (1851). Ensayo sobre dos cuestiones sociales. En Memorias sobre la extinción de la mendicidad y el establecimiento de las Juntas de Caridad... (pp. 9-108). Madrid: Imprenta del Nacional de Sordo-Mudos. 
El Constitucional (1837, 28 de agosto). Imposibilidad de que Cataluña se declare nunca independiente. El Constitucional, pp. 2-3.

Espectáculos públicos (1868, 2 de febrero). El Lloyd de España-Barcelona-, p. 3.

Estrany, J. (1857, 10 de noviembre). Lecciones de gimnástica. Diario de Barcelona, p. 9299.

Estrany, J. (1862, 7 de noviembre). Gimnasio. Diario de Barcelona, p. 9939.

Estrany, J. (1868, 6 de septiembre). Gimnasio Normal para ambos sexos. El Principado, p. 5682.

F. [El Corresponsal] (1839a, 8 de diciembre). Gimnasio Civil de Valencia. Diario de Barcelona, pp. 5196-5197.

F. [El Corresponsal] (1839b, 26 de noviembre). Gimnasio Civil de Valencia. El Corresponsal (Madrid), p. 4.

Fernández Sirvent, R. (2005). Francisco Amorós y los inicios de la educación física moderna. Biografía de un funcionario al servició de España y Francia. Alicante: Publicaciones de la Universidad de Alicante.

Figueroa, J. L. (1857, 31 de octubre). La Época, p. 2.

Figuerola, L. (1841). Manual Completo de enseñanza simultánea, mutua y mixta. Barcelona: Imp. del Constitucional.

Figuerola, L. (1844). Guía legislativa e inspectiva de instrucción primaria, Librería Europea de Hidalgo. Madrid: Imp. Catalana.

Foix, J. B. (1858). Apuntes sobre la terapéutica general. Resumen de las lecciones dadas en la Facultad de Medicina de la Universidad Literaria de Barcelona. Barcelona Imp. Casa Piferrer.

Font, J. (1855). Investigaciones acerca del Cólera-Morbo Asiático, su origen, sus causas, su curacion. Barcelona: J. Bosch y Cia.

Fontana, J. (2015 [2007]). La época del liberalismo. En J. Fontana y R. Villares (dirs.), Historia de España. vol. 6. Madrid: Marcial Pons. 
Fradera, J. M. (2003). Cultura nacional en una sociedad dividida: Cataluña, 18381868. Madrid: Marcial Pons.

Gacetillas (1864, 8 de febrero). El Lloyd Español-Barcelona-, p. 1.

Gimnasio Español (1863, 26 de octubre). La Corona-Barcelona-, p. 4.

Gimnástica (1857, 3 de noviembre). Gimnástica. La Corona-Barcelona-, p. 6.

Gimnástica (1858, 16 de enero). Gimnástica. La Corona-Barcelona-, p. 7.

H. (1860, 17 de junio). Revista de París. Diario de Barcelona, pp. 5620-5621.

Hermanos Vall (1862, 1 de noviembre). Gimnasio Higiénico Catalán. Diario de Barcelona, p. 9772.

Instituto Manicomio San Baudilio de Llobregat (1856, 16 de enero). Diario de Barcelona, pp. 452-453.

Jullien, M. A. (1840). Ensayo General de educación física, moral e intelectual con un plan de educación práctica para la infancia, la adolescencia y la juventud. Valencia: Ventura Lluch.

La regeneración física de la especie humana por medio de la gimnasia racional (1848, 8 de abril). El Clamor Público,-Madrid-pp. 2-3.

Libros (1861, 18 de agosto). Diario de Barcelona, p. 7082.

Lladó, J. (1868). Nociones de gimnástica higiénica, aplicables a las escuelas de instrucción primaria de uno y otro sexo como elemento de educación física y de utilidad en todas las edades y para todas las clases de sociedad. Barcelona: Lib. de Juan Bastinos e hijo.

Llaverias, A. (1906, 3 de marzo). Gimnasio Bricall. Los Deportes -Barcelona-, p. 133.

Londe, C. (1829). Nuevos elementos de higiene. Madrid: Imp. que fue de Fuentenebro.

M. (1850, 22 de julio). Varias personas que asistieron á los ejercicios... Diario de Barcelona, p. 3824. 
Mañé, J. (1891). Un precursor del regionalismo español. Cartas de D. Juan Mañé Flaquer, del año 1855. Revista la España Regional, 60, pp. 97-111.

Marfany, J. LI. (2017). Nacionalisme espanyol i catalanitat. Cap a una revisió de la Renaixença. Barcelona: Edicions 62.

Masriera, A. (1924). Los buenos barceloneses: Hombres, costumbres y anécdotas de Barcelona ochocentista (1850-1870). Barcelona: Ed. Poliglota.

Miret, A. (1931, 1 de marzo). Com i quan nasqué a Barcelona la gimnástica. Portaveu del Club Femení i d'Esports de Barcelona, p. 10.

Moliner, A. (2016). La recepción de las ideas revolucionarias (radicales, socialistas y republicanas) en Cataluña en el siglo XIX. Revista de História das Ideias, 4, pp. 239-266. https://doi.org/10.14195/2183-8925_34_10.

Monés, J. (2000). L'escola Normal de Barcelona. Barcelona: Publicacions Universitat de Barcelona.

Monlau, P. F. (1840). De la instrucción pública en Francia, ensayo sobre su estado en 1838 y 1839 . Barcelona: Antonio Bergnes.

Monlau, P. F. (1843, 9 de junio). Barceloneses. Diario de Barcelona, pp. 2456-2457.

Monlau, P. F. (1846). Elementos de higiene privada: o arte de conservar la salud del individuo. Madrid: Imp. de Pablo Riera.

Monlau, P. F. (1847). Elementos de higiene pública, tomo II. Barcelona: Imp. de Pablo Riera.

Monlau, P. F. (1858). Higiene del matrimonio ó El libro de los casados. Madrid: Rivadeneyra.

Moratones, A. (1859a, 8 de abril). Gimnasio higiénico recreativo. Diario de Barcelona, p. 3842.

Moratones, A. (1859b, 7 de junio). Natación. Diario de Barcelona, p. 6123.

Moratones, A. (1862, 28 de septiembre). Gimnasio Higiénico y Curativo. Diario de Barcelona, p. 8677. 
Moratones, A. (1863). Nociones elementales de gimnasia, para jóvenes de ambos sexos... Barcelona: Imp. Joaquín Bosch.

Morel, B. A. (1857). Traité des dégénérescenses physiques, intellectueles et morales de la espèce humaine. Paris: J. B. Bailliere.

Mosse, G. (2005). La nacionalización de las masas. Simbolismo político y movimiento de masas en Alemania desde las Guerras Napoleónicas al Tercer Reich. Madrid: Marcial Pons.

Mosse, G. L. 2000. La imagen del hombre. La creación de la moderna masculinidad. Madrid: Talasa.

Noticias extranjeras (1820, 18 de mayo). Diario Constitucional, político y mercantil de Barcelona, p. 2.

Nuevo Circo Olímpico (1847, 1 de enero). Diario de Barcelona, p. 9.

Patio de las Magdalenas (1842, 13 de noviembre). Diario de Barcelona, p. 4335.

Pons, M. (1850). Lecciones de terapéutico general. Barcelona: Imp. y Lib. de la Sra. V. E. H. de Mayol.

Presas, L. (1855). Guerra a muerte al cólera morbo asiático. Barcelona: Lib. de Joaquín Verdaguer.

Prot, F. (2010). Kinesiology - the science of movement in relation to education, hiyene and therapy. A piece of the legacy of Nicolas Dally (1795-1862) for contemporary kinesiology scholars and professionals. Annales Kinesiologiae, 1(1), pp. 7-21.

Pujadas, A. (1872). El Manicomio de San Baudilio de Llobregat - Sucinta Historia de la Ciencia ...Barcelona: Imp. El «Porvenir» de la Viuda de Bassas.

Quadras, F. (1861, 16 de noviembre). Barcelona. Diario de Barcelona, p. 10102.

Quadras, F. (1862, 8 de octubre). Barcelona. La afición a los ejercicios gimnásticos... Diario de Barcelona, p. 8980.

Ramis, J. (1865). Una verdad o consideraciones sobre la utilidad de la Gimnástica. Barcelona: Imp. de Gómez e Inglada. 
Roth, J. M. (1823). Ordenanzas para el régimen y gobierno del primer Instituto Gimnástico-Militar, que deberán observar sus alumnos, individuos del batallón de jóvenes. Barcelona: Imp. Ayuntamiento Constitucional.

Rovira, A. (1856). Tratado de extinción de incendios. Barcelona: Imp. de la Publicidad, Barcelona. «Ejercicios gimnásticos», pp. 203-204.

Sáenz-Rico, A. (1973). La educación general en Cataluña durante el Trienio Constitucional (1820-1823). Barcelona: Publicaciones de la Cátedra de Historia Universal, Departamento de Historia Contemporánea.

Sainz, J. (1842, 31 de marzo). Examen filosófico de la Alemania desde la revolución francesa. Revista de España, pp. 249-265.

Schreber, D. G. M. (1861). Manual popular de gimnasia de sala médica é higiénica. Madrid: Bailly-Bailliere.

Sudre, A. (1856). Historia del comunismo o refutación histórica de las utopías socialistas. Barcelona: Imp. de A. Brusi.

Teatro Principal (1852, 26 de marzo). Espectáculos. Diario de Barcelona, p. 1.

Thomase, E. (1851, 2 de diciembre). Aviso para los que padecen. Diario de Barcelona, pp. 7118-7119.

Thomase, E. (1853, 16 de junio). La esgrima es el principal ejercicio de la gimnástica. Diario de Barcelona, p. 4302.

Thomase, E. (1857, 24 de noviembre). Gimnástica higiénica. Diario de Barcelona, p. 9707.

Torrebadella-Flix, X. (2015). Orígenes de la educación física en las escuelas públicas: El caso particular del Ayuntamiento de Barcelona durante el siglo XIX. Cabás, 13, pp. 38-64.

Torrebadella-Flix, X. (2020a). El gimnasio moderno en España y Francia. Una relación franco-española equidistante y divergente en el siglo XIX. RICYDE. Revista Internacional de Ciencias del Deporte, 16(60), pp. 153-159. https://doi. org/10.5232/ricyde2020.06004. 
Torrebadella-Flix, X. (2020b, en prensa). Subjetividades y dispositivos sobre el control del cuerpo femenino en la génesis del gimnasio moderno. Arenal.

Torrebadella-Flix, X., Olivera-Betrán, J., y M-Bou, M. (2015). Origin and Institutionalisation of Sports and Gymnastics Associations in NineteenthCentury Spain (1822-1900). Apunts. Educación Física y Deportes, 119, pp. 7-54. http://dx.doi.org/10.5672/apunts.2014-0983.cat.(2015/1).119.01.

Torrebadella-Flix, X., Rivero-Herraiz, A., y Sánchez-García, R. (2019). When the Elites Began Going to the Gym: The Professional and Social Spaces of the First Hygienic Gymnasiums in Madrid, 1860-69. The International Journal of the History of Sport. https://doi.org/10.1080/09523367.2019.1691531.

Torrebadella-Flix, X., y Vicente-Pedraz, M. (2016). La gimnástica como dispositivo antionanista en la conformación de la educación física escolar en el siglo XIX en España. El nacimiento de una disciplina escolar. Movimento, 22(1), pp. 99-114. https://doi.org/10.22456/1982-8918.53988.

Torrebadella, X. (2011). La educación física y la actividad gimnástico-deportiva de las mujeres a partir de la bibliografía especializada del siglo XIX. Arenal, 18(1), pp. 147-179.

Torrebadella, X. (2012a). Antecedentes en la institucionalización de la gimnástica militar española (1800-1852). Revista de Historia Militar, 111, pp. 185-244.

Torrebadella, X. (2012b). L'aportació dels metges de Lleida a l'educació física catalana del segle XIX. Temps d'Educació, 43, pp. 109-130.

Torrebadella, X. (2012c). Las primeras tesis doctorales de la educación física en el espacio científico y profesional sobre la medicina española. Pecia Complutense, 16, pp. 58-88.

Torrebadella, X. (2013a). Del espectáculo acrobático a los primeros gimnasios modernos. Una historia de las compañías gimnástico-acrobáticas en la primera mitad del siglo XIX en España. Aloma: Revista de Psicologia, Ciències de l'Educació i de l'Esport, 31(2), pp. 67-84.

Torrebadella, X. (2013b). Gimnástica y educación física en la sociedad española de la primera mitad del siglo XIX. Lleida: Universitat de Lleida. 
Torrebadella, X. (2013c). La educación física femenina en el período Isabelino (18331868): Teresa Castellanos de Mesa, primera profesora española de gimnástica. Ágora para la educación física, 15(1), pp. 20-39.

Torrebadella, X. (2014). La influencia de la profesión médica en la educación física española del siglo XIX: Análisis social del Manual popular de gimnasia de sala, médica e higiénica del Dr. Schreber. Cultura, Ciencia y Deporte, 9(26), pp. 163176. https://doi.org/10.12800/ccd.v9i26.434.

Torrebadella, X. (2017). Del mito al olvido: el Conde de Villalobos y la gimnástica española (1841-1867). ODEP. Revista Observatorio del Deporte, 3(2), pp. 69111.

Torrebadella, X., y Arrechea, F. (2015). Los orígenes de una ciudad olímpica. La vida gimnástica-deportiva en la Barcelona decimonónica. Madrid: CIHEFE.

Torrebadella, X., y Olivera, J. (2012). Las cien obras clave del repertorio bibliográfico español de la educación física y el deporte en su proceso de legitimación e institucionalización (1807-1938). Revista General de Información y Documentación, 22, 119-168. http://dx.doi.org/10.5209/rev_RGID.2012. v22.39669.

Valencia 16 de noviembre (1839, 20 de noviembre). Instituto Gimnástico del Señor Amorós. El G. Nacional-Barcelona-, p. 2.

Vall, F. (1862, 11 de noviembre). Gimnasio Higiénico de Barcelona. Diario de Barcelona, p. 10062.

Vall, F., y Vall, L. (1860, 1 de enero). Gimnasio para ambos sexos. Diario de Barcelona, p. 26.

Vall, J. (1854, 31 de octubre). Enseñanza de gimnasia. Diario de Barcelona, p. 7636.

Vall, J., y Vall, F. (1867, 18 de noviembre). Gimnasio Barcelonés. El Principado, p. 7629.

Ventosa, E. (1860). La regeneración de España. Barcelona: Lib. Salvador Manero.

Vicente-Pedraz, M., y Brozas-Polo, M. P. (2017). El triunfo de la regularidad: gimnasia higiénica contra acrobacia en la configuración física escolar en la segunda 
mitad del siglo XIX. Revista Brasilera do Sporte, 39(1), pp. 49-55. http://dx.doi. org/10.1016/j.rbce.2015.10.006.

Vicente-Pedraz, M., y Torrebadella-Flix, X. (2015). La gimnástica como dispositivo antionanista en la conformación de la educación física escolar en el siglo XIX en España. Recepción de los discursos. Movimento, 21(4), 1037-1049. http:// www.seer.ufrgs.br/index.php/Movimento/article/view/53986/36091. https:// doi.org/10.22456/1982-8918.53986.

Vicente-Pedraz, M., y Torrebadella-Flix, X. (2017). El dispositivo gimnástico en el contexto de la medicina social decimonónica española. De las políticas higiénicas a los discursos fundacionales de la "educación física». Asclepio, 69(1), p. 172. http://dx.doi.org/10.3989/asclepio.2017.04.

Vicente-Pedraz, M., y Torrebadella-Flix, X. (2019). Los primeros gimnasios higiénicos: espacios para sanar y corregir el cuerpo. Disparidades. Revista de Antropología, 74(1), pp. 165-181. https://doi.org/10.3989/dra.2019.01.002.

Vigarello, G. (2005). Corregir el cuerpo. Historia de un poder pedagógico. Buenos Aires: Nueva Visión.

Vilanou, C. (2011). Balmes, educador. Espíritu: cuadernos del Instituto Filosófico de Balmesiana, 60(142), pp. 261-309.

Vilanou, C. V. (2007). Jaime Balmes (1810-1848): la pedagogía del sentido común. Anuario de pedagogía, 9, pp. 419-447.

Villacañas, J. L. (2017). Historia del poder político en España (3. ed ed.). Barcelona: RBA. 
Página intencionadamente en blanco. 